Discussion Papers in Economics

Climate Policy and Innovation in the Absence of Commitment

Ashokankur Datta

E. Somanathan

December 2010

Discussion Paper 10-09

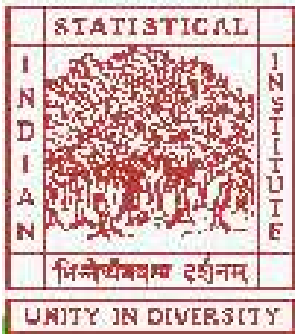

Indian Statistical Institute, Delhi

Planning Unit

7, S. J. S. Sansanwal Marg, New Delhi 110016, India 


\title{
Climate Policy and Innovation in the Absence of Commitment *
}

\author{
Ashokankur Datta ${ }^{\dagger}$ and E. Somanathan ${ }^{\ddagger}$
}

December 30, 2010

\begin{abstract}
It is well-recognized that new technology is a crucial part of any solution to the problem of climate change. But since investments in research and development take time to mature, price and quantity instruments, i.e., carbon taxes and cap-and-trade, run into a commitment problem. We assume that the government cannot commit to the level of a policy instrument in advance, but sets the level to be optimal ex-post. Under these assumptions, we show that when the supply curve of dirty (emission-producing) energy is flat, then an emissions tax is ineffective in promoting $\mathrm{R} \& \mathrm{D}$ into green (emission-free) energy while an emissions quota (i.e., cap and trade) can be effective. A subsidy to $\mathrm{R} \& \mathrm{D}$ is welfare-reducing. More realistically, when the supply curve of dirty energy is upward-sloping, then both tax and quota regimes can be effective in promoting $\mathrm{R} \& \mathrm{D}$ into emission-free technology. In this case, a tax generally induces more R \& D than a quota. When the supply curve is sufficiently steep compared to the demand curve, a subsidy to $\mathrm{R} \& \mathrm{D}$ can expand the range of parameter values under which $\mathrm{R} \& \mathrm{D}$ occurs and this can be welfare-improving. If there is sufficient uncertainty about whether a climate policy will be adopted ex-post, then subsidizing $R \& D$ is an even more attractive policy option since a welfare-improving subsidy to $\mathrm{R} \& \mathrm{D}$ exists under a wider range of circumstances.
\end{abstract}

${ }^{*}$ We are grateful to Amrita Ray Chaudhuri, Antony Millner, and participants of seminars at Motu Economic and Public Policy Research in Wellington, Singapore Management University, the National Research Conference on Climate Change at IIT, Delhi, the University of Oslo, the 4th World Congress of Environmental and Resource Economists, the Triangle Resource and Environmental Economics seminar, and the 12th Occasional California Workshop on Environmental and Resource Economics for helpful comments.

${ }^{\dagger} \mathrm{PhD}$ candidate, Planning Unit, Indian Statistical Institute, Delhi. E-mail: ashok5r@isid.ac.in

${ }^{\ddagger}$ Professor, Planning Unit, Indian Statistical Institute, Delhi, and Visiting Professor, Princeton University. E-mail: som@isid.ac.in 


\section{INTRODUCTION}

Economic instruments for pollution control in general and climate policy in particular are considered superior to traditional regulation and subsidies because they are believed to induce adjustment on all appropriate margins in a least-cost way. Analyses of the virtues of these instruments, however, are typically made in a static context.

Avoiding dangerous climate change and ocean acidification involves a halt to, and possibly even a reversal of, the build-up of carbon dioxide in the atmosphere. It is, therefore, clear that energy technologies that replace those emitting carbon dioxide are a necessary part of any solution. This makes technological advance to reduce the cost of carbon-free energy an important target of climate policy.

In order to induce investment in research and development, incentive-based instruments such as emissions taxes and carbon cap and trade have to be expected to be in place after the new technology comes to market. This can be several years after the decision to invest in $\mathrm{R} \& \mathrm{D}$ is made. Policies announced or put in place today can be changed. To put it simply, there is a commitment problem. This commitment problem does not apply to policies put in place today that lower the cost of $\mathrm{R} \& \mathrm{D}$, such as subsidies or complementary investments by public-sector entities. We compare the effects of an emissions tax, an emissions quota with tradeable permits, and R \& D subsidies on a firm's incentive to conduct R \& D in the absence of commitment by the government.

While there is a considerable literature on the role of emission-reducing R \& D, Kneese and Schulze (1975), Marin (1978), Downing and White (1986), Milliman and Prince (1989), Jung et al. (1996), Denicolo (1999), Fischer et al. (2003), most of it concerns technologies that reduce the rate of emissions. This approach is suited to the study of end-of-pipe abatement technologies, or others where emissions rates can be reduced by changing the quality of fuel. It is of limited applicability in studying carbon dioxide emissions, the most significant contributor to climate change. Of greater significance in the climate context are technologies that replace carbon-based fuels with an entirely different source of energy, such as solar, wind, or nuclear energy. In recent years, Montgomery and Smith (2005) studied the commitment problem in climate policy in a framework where innovation leads to development of zero carbon technologies. They concluded that standard market-based environmental policy tools cannot create credible incentives for R \& D. A crucial assumption in their paper was that the $\mathrm{R} \& \mathrm{D}$ sector is competitive. Thus their negative result is a consequence of the non-appropriability of the returns from $\mathrm{R} \& \mathrm{D}$. In our work, we assume a monopolistic R \& $\mathrm{D}$ sector so that the returns from $\mathrm{R} \& \mathrm{D}$ are appropriable. We obtain results that are less pessimistic than Montgomery and Smith (2005). 
The paper whose framework most closely resembles our own is that of Denicolo (1999). Like us, Denicolo considers a monopolistic firm that decides how much to invest in $\mathrm{R} \& \mathrm{D}$ on the basis of its expectation about the level of an emissions tax or quota with tradeable permits. Denicolo assumes that the extent of emission reduction per unit of output is an increasing function of the amount invested in $\mathrm{R} \& \mathrm{D}$ but that the private marginal cost of producing a unit of output is unaffected by $\mathrm{R} \& \mathrm{D}$. In contrast, we assume that $\mathrm{R} \& \mathrm{D}$ is used to reduce the marginal cost of zero-emission technologies. Our assumption is intended to model replacement technologies of the kind mentioned above, while his is better suited to modeling end-of-pipe abatement of a particular kind: one in which there is a sunk cost of abatement ( $\mathrm{R} \& \mathrm{D})$ but no variable cost. Denicolo shows that if the government sets the level of the emissions tax or aggregate quota to be optimal ex-post, that is, after the result of $\mathrm{R}$ $\& \mathrm{D}$ is realized, then tax and quota policies are equivalent. They induce the same $\mathrm{R} \& \mathrm{D}$. In contrast, we show that in our framework in which $\mathrm{R} \& \mathrm{D}$ affects the cost of a zero-emission technology, a tax can never induce R \& D while a quota can do so. ${ }^{1}$ Scotchmer (2009) uses a framework similar to that of Denicolo and obtains similar results.Kolstad (2010) develops a model without dynamic inconsistency. He models technological progress on the lines of Denicolo (1999) and shows that a single instrument in the form of a tax or an abatement quota can ensure social optimality.

In this paper, we compare the effects of tax and tradeable quota policies in the absence of commitment, and the role of $\mathrm{R} \& \mathrm{D}$ subsidies. ${ }^{2}$ In Section 2 we show that when the marginal cost of dirty (emission-producing) energy is constant, then an emissions tax is ineffective in inducing $\mathrm{R} \& \mathrm{D}$, while a quota can be effective. The reason for this is that a fall in the marginal cost of the emission-free technology as a result of $\mathrm{R} \& \mathrm{D}$ means that a lower tax is sufficient to allow the new technology to compete. Since a higher-than-necessary tax results in a welfare loss by giving the owner of the new technology monopoly power, the government reduces the emissions tax in response to successful $\mathrm{R} \& \mathrm{D}$. This destroys the incentive to do R \& D.

When the policy instrument is an emissions quota, we show that the government will reduce the quota when the emission-free technology gets less expensive (as long as it remains more costly than the dirty alternative), because the cost of reducing emissions has fallen.

\footnotetext{
${ }^{1}$ This result holds only under the assumption (common to Denicolo (1999)) that the marginal cost of the dirty technology is constant.

${ }^{2}$ We do not model the international aspect of the problem. In any case, the results are relevant for jurisdictions with large energy markets such as China, the United States, and the European Union. In fact, one attractive feature of technological improvements is that they may make international agreement easier to reach.
} 
This response induces $\mathrm{R} \& \mathrm{D}$. But we also show that the introduction of a technology that is less costly than the dirty alternative is inhibited. This is because the government response in such a case is the opposite: It increases the quota since it is no longer needed to contain emissions and only enhances the monopoly power of the green firm. We show that any subsidy to $\mathrm{R} \& \mathrm{D}$ investment that actually induces $\mathrm{R} \& \mathrm{D}$ is welfare-reducing when the marginal cost of dirty energy is constant.

Since fossil fuels are subject to increasing marginal costs of production when harder to reach mineral deposits have to be extracted, it is more realistic to assume that the supply curve of dirty energy is upward-sloping. We make this assumption in Section 3 of the paper. Now both tax and quota regimes can be effective in promoting $\mathrm{R} \& \mathrm{D}$ into emission-free technology but they are not equivalent. The results of Section 2 are reversed (for a sufficiently steep supply curve of dirty energy) and a tax generally induces more R \& D than a quota. When the supply curve of dirty energy is sufficiently steep compared to the demand curve for energy, a subsidy to R \& D can expand the range of parameter values under which $\mathrm{R} \& \mathrm{D}$ occurs and this can be welfare-improving.

Once we allow for the upward-sloping supply of dirty energy, then the owners of easily extractable fossil fuels have rents. The assumption that climate policy will be statically optimal ex-post is then questionable since fossil fuel rentiers will lobby to protect their rents. This will give rise to uncertainty about whether a climate policy will be adopted at all in the future. In Section 4, we assume that there is some probability that no climate policy will be adopted. We show that if this probability is sufficiently high, then the range of parameter values under which a welfare-improving subsidy to $\mathrm{R} \& \mathrm{D}$ exists is expanded.

\section{The MODEL WITH A CONSTANT MARGINAL COST OF DIRTY ENERGY}

\subsection{Structure of The ECONOMY}

There is a representative consumer who consumes two goods, energy $(e)$ and the numeraire good $(y)$. The consumer maximizes a quasi-linear utility function

$$
U(e)+y=a e-\frac{b}{2} e^{2}+y
$$

subject to

$$
P e+y=Y,
$$


where $\mathrm{P}$ is the price of energy and $\mathrm{Y}$ is the endowment with the consumer. Solving this problem gives the consumer's inverse demand function for energy

$$
P=D^{-1}(e)= \begin{cases}a-b e & \text { if } \quad e<\frac{a}{b} \\ 0 & \text { if } \quad e>\frac{a}{b}\end{cases}
$$

So $b$ is the slope of the marginal social benefit of energy.

Energy in the economy can be produced in two ways. There is a competitive industry that produces dirty energy $e_{d}$, with a pollutant being emitted as a by-product. This has a constant average and marginal cost of production of zero. ${ }^{3}$ Energy can also be produced without any pollution emissions. The quantity of this green energy is denoted by $e_{g}$. The marginal cost of producing green energy depends on the research and development investment made by a monopolist in the period before production occurs. If $I$ is investment measured in units of the numeraire good, then the marginal cost of green energy that will be realized next period is $g=g(I)$ given by

$$
g(I)= \begin{cases}\bar{g}-\left(\frac{I}{i}\right)^{\frac{1}{2}} & \text { if } 0 \leq I<i \bar{g}^{2} \\ 0 & \text { if } I \geq i \bar{g}^{2} \quad \text { where } \quad i>0\end{cases}
$$

Therefore,

$$
g^{\prime}(I)<0, \quad g^{\prime \prime}(I)>0, \quad g(0)=\bar{g}>0
$$

Equation (2.1.4) can also be written as:

$$
I:[0, \bar{g}] \rightarrow \mathbb{R}^{+} \quad \text { where } \quad I(g)=i(\bar{g}-g)^{2}
$$

$\frac{1}{i}$ measures the impact of investment on the marginal cost of green energy. The lower the value of $i$, the more sensitive the marginal cost of green energy is to $\mathrm{R} \& \mathrm{D}$ investment.

Emissions produce an externality that is not internalized by the consumer. We choose units so that one unit of dirty energy produces one unit of emissions and we suppose that the damage from emissions is linear so that $e_{d}$ units of dirty energy result in an external damage of $\delta e_{d}$. Thus $\delta$ is the (constant) marginal damage of dirty energy.

The sequence of events in the model is as follows: The government inherits from the past the choice of policy instrument: tax or quota. It is assumed that it cannot change this. The government chooses a subsidy rate for the firm's investment in research and development. Then the green firm chooses its investment in $\mathrm{R} \& \mathrm{D}$. In the next period, as a result of the green firm's R \& D, its marginal cost of production $g$ is realized. The government observes $g$ and then chooses the level of the quota or tax (as the case may be) with the objective

\footnotetext{
${ }^{3}$ We discuss the case of a positive marginal cost in Section 4.
} 
of maximizing social welfare. We assume that in the first period the government cannot credibly commit to the level of the quota or to the tax rate it will impose in the second period. However, it is committed to the kind of instrument it has inherited, whether that is a tax or a quota. The government is free to choose a non-binding quota or a zero tax. After observing the tax rate or the level of the quota, the green firm chooses its price and output. ${ }^{4}$

In reality, we believe that the choice of quota or tax is made by governments on the basis of their usefulness in the current period. Governments are not looking half a decade, or even several decades ahead at the effects on the technologies that become available. Once this choice is made, an institutional infrastructure is locked in around it, so it is not easily reversible. On the other hand, the effective level of the tax or quota can be altered by future legislatures or governments that react to the then prevailing conditions. This is the motivation for our assumptions above. Since we are interested in the effects of instruments on the incentive to innovate, we do not model production and emissions in the current period.

We assume that in the absence of a green firm, it is socially optimal to produce a positive level of dirty energy, and that the initial marginal cost of the green firm is below the marginal social value of energy at $e=0$. That is,

Assumption $2.1 a \geq \max (\delta, \bar{g}) \geq 0$

Now if $g=0$, then the green firm's monopoly price is $\frac{a}{2}$. For positive $g$ the monopoly price will be $\frac{a+g}{2}$. (This is easily checked.)

The green firm's profit net of investment in $\mathrm{R} \& \mathrm{D}$ is denoted by

$$
\Pi=\pi-I
$$

where $\pi$ denotes gross profit in the last stage of the game. Similarly, social welfare net of investment in $\mathrm{R} \& \mathrm{D}$ is denoted by

$$
W=w-I
$$

where $w$ is the gross social welfare that the government maximizes in the second stage of the game:

\footnotetext{
${ }^{4}$ Even with commitment, a single policy instrument will not be able to achieve the first best. The number of instruments required to achieve a vector of policy targets cannot be less than the number of elements in the vector. Since we have two targets: the level of abatement, given a marginal cost of abatement and the marginal cost of abatement itself, a single instrument is unable to achieve it (Tinbergen, 1964).

In Kolstad (2010), optimality is achieved as he assumes that policy targets abatement rather the level of emissions, thus restricting the number of margins along which adjustment can take place.
} 


$$
w=a e-\frac{b}{2} e^{2}+Y-g e_{g}+\delta e_{d}
$$

\subsection{The TAx Regime}

Proposition 1 There will be no investment in research and development under the tax regime.

Proof:

Suppose the firm chooses $g>\delta$ (which can happen only if $\bar{g}>\delta$ ) in the first stage. Then the social marginal cost of green energy is greater than that of dirty energy. Thus the optimal tax is $\delta$, the difference between the social and private marginal costs of energy production. The green firm will not produce and so will incur a net loss with $\pi=-I(g) \leq 0$, where equality holds only when $g=\bar{g}$.

If $g \leq \delta$, then the optimal tax is infinitesimally greater than $g$. This is just sufficient to drive the dirty firms out of the market, but not enough to allow the green firm to exercise its monopoly power to restrict output. Now the green firm can only charge the tax, which is just infinitesimally greater than $g$. Thus the green firm incurs a loss of $-I(g) \leq 0$.

Therefore, the green firm must set $I=0$ if it is to avoid a loss.

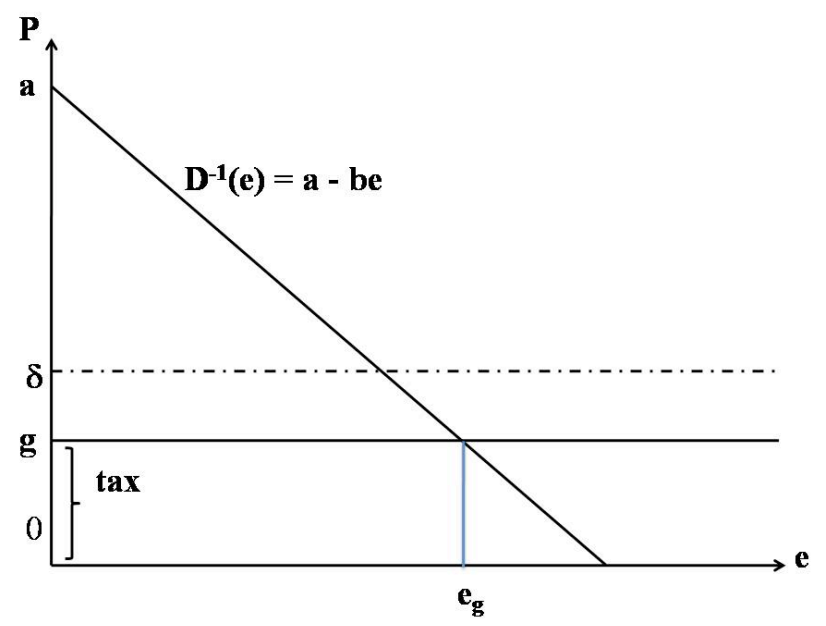

Figure 1: Tax Regime with $g<\delta$ 
The optimal tax falls with $g$, wiping out the incentive to do R \& D.

\subsection{The Quota Regime}

The model is a sequential game between the government and the green firm with three stages,

1. The green firm choosing investment.

2. The government choosing an emissions quota $q$.

3. The green firm choosing its price and output.

We use backward induction to solve it.

\subsubsection{Response of firms given that investment has been made and a quota chosen by government.}

Suppose $q \geq D(g)$ for some $g \geq 0$. Then the price of tradeable emissions permits will be $D^{-1}(q)$ and the dirty sector can supply energy at a price less than the green firm's cost. Thus the green energy firm will not produce. The price of energy will be $D^{-1}(q)$ and energy produced will be equal to the level of quota.

Now suppose $q<D(g)$ for $g \geq 0$. The green firm faces a residual demand curve of $D(P)-q$ for $P$ in the relevant range $D^{-1}(q) \geq P \geq 0$. It acts as a monopolist in this market and chooses $e_{g}$ to maximize

The profit function of the R\&D firm is :

$$
\begin{aligned}
\pi & =e_{g}\left[D^{-1}\left(e_{g}+q\right)-g\right] \\
& =e_{g}\left[a-b\left(q+e_{g}\right)-g\right]
\end{aligned}
$$

$\pi$ is concave in $e_{g}$ and there is no corner solution. The monopoly price is the average of marginal cost and the highest point of the residual demand curve $D^{-1}(q)$. Thus the output

of clean energy and total energy, the price of energy and the profit of the green firm are respectively:

$$
\begin{aligned}
e_{g}(g, q) & =\frac{1}{2}[D(g)-q] \\
& =\frac{a-b q-g}{2 b}
\end{aligned}
$$




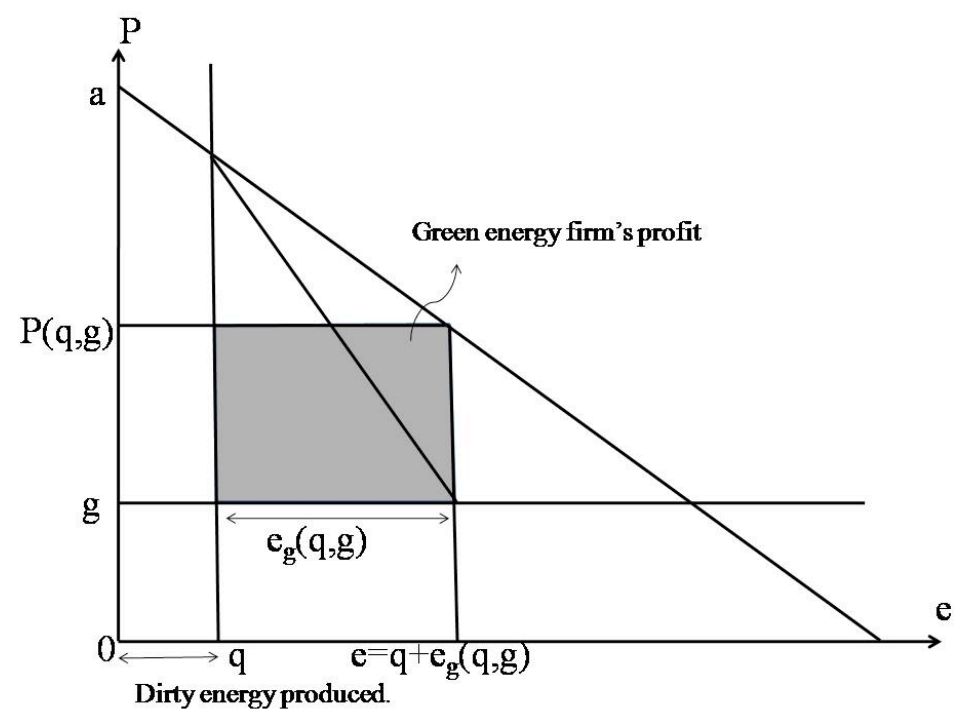

Figure 2: Quota Regime: $q<D(g)$

$$
\begin{aligned}
e(g, q) & =\frac{1}{2}[D(g)+q] \\
& =\frac{a+b q-g}{2 b} \\
P(g, q) & =\frac{1}{2}\left(D^{-1}(q)+g\right) \\
& =\frac{a-b q+g}{2} \\
\pi(g, q)=\frac{1}{4}[D(g)-q]\left[D^{-1}(q)-g\right] & \\
= & \frac{(a-b q-g)^{2}}{4 b}
\end{aligned}
$$

2.3.2 Optimal selection of $q$ by the government, after observing the green firm's choice of $g$ and taking the green firm's reaction function as a constraint in its welfare-maximizing exercise.

In this section we make the assumption that $\delta<\bar{g}$. If $\bar{g}<\delta$, there would be no emissions problem, only a problem of making emission control less expensive.

Assumption $2.2 \delta<\bar{g}$ 
If $g>\delta$, the social marginal cost of green energy is greater than that of dirty energy, and it would be inefficient to allow the green firm to operate. So the optimal $q \geq D(g)$. Optimality is attained at $q=D(\delta)$ where the marginal social cost of dirty energy equals the marginal social benefit from energy consumption.

Now consider the case $g<\delta$. Now the marginal social cost of green energy is lower than that of dirty energy. While a stricter quota brings a welfare gain from reduced emissions, it inflicts a welfare loss from lower consumption of energy. The government chooses the quota taking this trade off into account.

Starting with $q=D(\delta)$, note that the marginal social benefit of tightening the quota is

$$
\begin{aligned}
& \delta-g-\frac{\partial e}{\partial q}(P(q, g)-g) \\
& =\delta-g-\frac{1}{2}\left[\frac{1}{2}\left(D^{-1}(q)-g\right)\right] .
\end{aligned}
$$

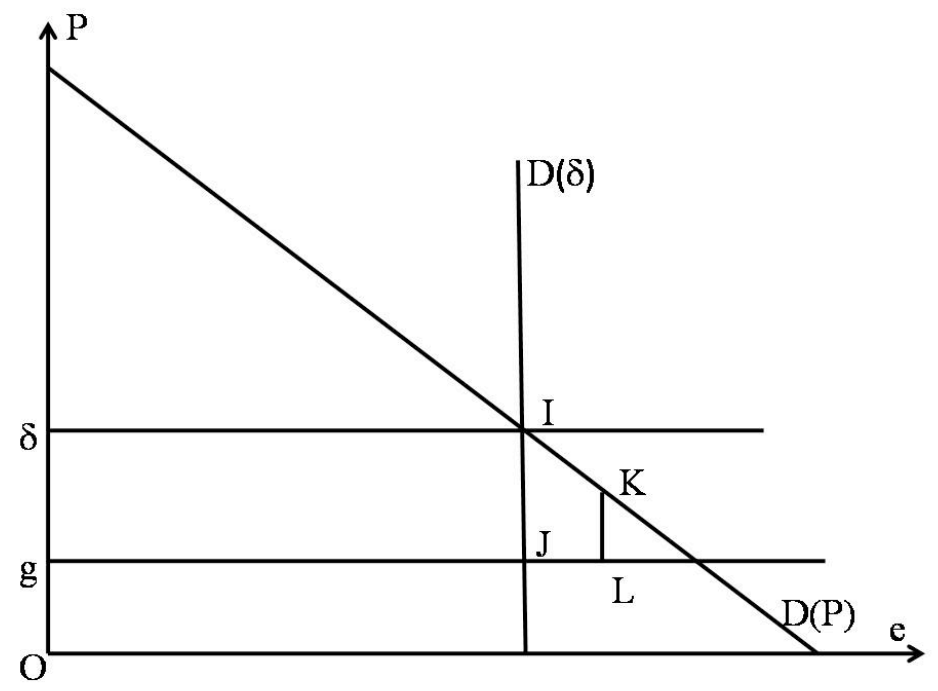

Figure 3: Quota Regime: Sub-optimality of $q=D(\delta)$ when $g^{0}<g<\delta$

$\delta-g(=\mathrm{IJ}$ in Figure 3) is the marginal reduction in the social cost of energy as dirty energy is replaced by clean energy while $\frac{1}{2}\left(D^{-1}(q)-g\right)(=$ KL in Figure 3$)$ is the marginal loss of social surplus when energy consumption falls in response to the decrease in $q$. When $q=D(\delta)$, the expression above equals $\frac{3}{4}(\delta-g)>0$. Thus the optimal $q<D(\delta)$. 
In fact, note that for any $q$, if $e(q, g)>D(\delta)$, then $P(q, g)<\delta$, so

$$
\delta-g>\frac{1}{2}(P(q, g)-g) .
$$

Thus, total energy consumption must fall when $g$ falls below $\delta$. As will be seen shortly, this fact has important implications for the welfare effects of an R \& D subsidy.

Differentiating $w$ with respect to $q$ in 2.1.6 and using 2.3.1 and 2.3.2, we find that at the optimal quota,

$$
\delta-g=\frac{1}{4}\left(D^{-1}(q)-g\right) .
$$

It is clear from this that if $g$ falls, then $q$ must also fall to restore equality. Thus, in contrast to the tax regime, a fall in $g$ induces a tightening of the emissions quota, thus reinforcing the incentive for the green firm to conduct R \& D. Solving equation 2.3.6 for $q$, we find that the optimal quota is given by

$$
q(g)=\left\{\begin{array}{lll}
D(\delta), & \text { if } & g \geq \delta \\
\max \frac{a+3 g-4 \delta}{b}, 0 & \text { if } & g<\delta
\end{array}\right.
$$

From now on, we ignore corner solutions in $q$ for the sake of simplicity. In other words, we assume that the externality from emissions is not high enough to justify setting a zero quota. It follows from 2.3.7 that the required assumption is

Assumption $2.3 a>4 \delta$.

\subsubsection{Optimal choice of investment (and marginal cost) by the green firm given the} reaction function of the government.

The green firm's net profit function is

$$
\begin{aligned}
\Pi(g) & =\pi(g, q(g))-I(g) \\
& \left.=\frac{4}{b}(\delta-g)^{2}-i(g-\bar{g})^{2} \quad \text { (using }(2.3 .4) \text { and } \quad(2.3 .7)\right), \\
& <0 \quad \text { at } g=\delta .
\end{aligned}
$$

Now

$$
\begin{aligned}
\Pi^{\prime}(g) & =-\frac{8}{b}(\delta-g)-2 i(g-\bar{g}) \\
& >0 \quad \text { at } g=\delta .
\end{aligned}
$$


Unless the positive slope of $\Pi$ at $g=\delta$ is reversed at a lower value of $g$, investment in $\mathrm{R} \&$ $\mathrm{D}$ is ruled out. Now

$$
\Pi^{\prime \prime}(g)=\frac{8}{b}-2 i .
$$

It follows immediately that $\mathrm{R} \& \mathrm{D}$ can take place only if $\Pi$ is convex and, therefore, if and only if $\Pi>0$ at $g=0$. This argument is summarized in

Proposition 2 The quota regime induces $R \& D$ with $g=0$ provided the marginal cost of green energy is sufficiently sensitive to $R \& D$ investment, that is, if (and only if) $i<\frac{4 \delta^{2}}{b \bar{g}^{2}}$.

This is illustrated in the figure below.

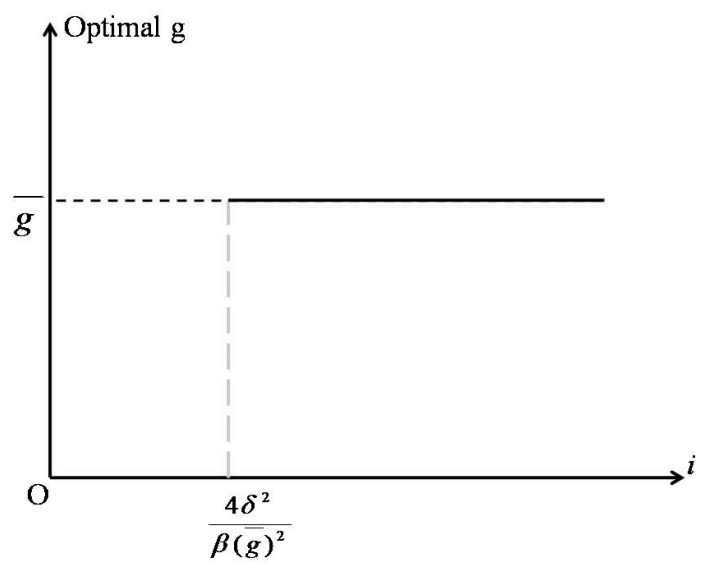

Figure 4: Optimal Choice of $g$ in the quota regime.

\subsection{Welfare Analysis}

We now compare social welfare under the tax and quota regimes. Under the tax regime, since no R \& D is induced and the green firm does not operate, welfare is simply the utility of energy consumption less the total social damage from dirty energy consumption. (We can ignore the term $Y$ in 2.1.6 since it is constant.) This is consumer surplus given by the area of $\triangle a \delta G$ in Figure 5 .

For values of $i$ greater than $\frac{4 \delta^{2}}{b \bar{g}^{2}}$, there is no investment in the quota regime either, the quota is set to internalize the externality, and energy consumption and welfare are identical to what would prevail under the tax regime.

If $i<\frac{4 \delta^{2}}{b \bar{g}^{2}}, \mathrm{R} \& \mathrm{D}$ is induced and the marginal cost of green energy falls to 0. Social welfare $w$ (without deducting investment in $\mathrm{R} \& \mathrm{D}$ ) is now ${ }^{5}$

\footnotetext{
${ }^{5}$ In drawing the figure in this way, we are making use of the remark made in Section 2.3.2 that total energy consumption is less than $D(\delta)$.
} 


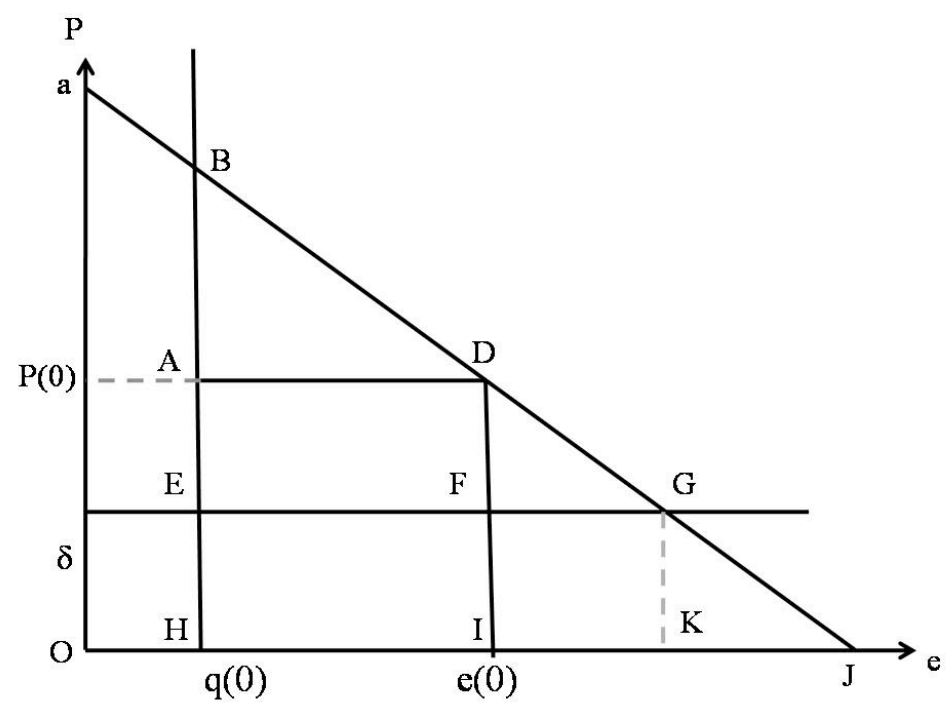

Figure 5: Welfare Analysis of Tax and Quota Regimes

the area of quadrilateral $a B E \delta)$ t the area of quadrilateral $B D I H$.

Thus, gross welfare under the quota regime exceeds welfare under the tax regime by

$$
\triangle w=\text { the area of the rectangle } E F I H-\text { the area of } \triangle D F G .
$$

Using 2.3.1 and 2.3.7,

$$
\text { the area of rectangle } E F I H=\frac{2 \delta^{2}}{b} .
$$

Using 2.3.2, 2.3.3, and 2.3.7,

$$
\text { the area of } \triangle D F G=\frac{\delta^{2}}{2 b} \text {. }
$$

Therefore,

$$
\triangle w=\frac{3 \delta^{2}}{2 b}
$$

Hence, a quota regime will offer higher net welfare than a tax regime if $\Delta w>i \bar{g}^{2}$ that is, if $i<\frac{3}{2} \frac{\delta^{2}}{b \bar{g}^{2}}$. (If this condition holds, then the hypothesis of Proposition 2 will be satisfied and R \& D investment will occur.) This argument is summarized as

Proposition 3 A quota regime that induces $R \quad \& \quad D$ results in higher welfare than a tax regime (that never induces $R \& B$ ) provided the marginal cost of green energy is sufficiently sensitive to $R \& D$ investment, that is, if $i<\frac{3}{2} \frac{\delta^{2}}{b \bar{g}^{2}}$. If $\frac{3}{2} \frac{\delta^{2}}{b \bar{g}^{2}}<i<\frac{4 \delta^{2}}{b \bar{g}^{2}}$, then the $R \&$ \& induced by the quota regime is socially too expensive. 


\subsection{The Role of an R \& D Subsidy}

Proposition 4 In a tax regime, an $R \mathscr{E} D$ subsidy is ineffective (has no impact on $R \& B D$ ). Under a quota regime, an $R \mathscr{E} D$ subsidy is either ineffective, or, if effective, reduces welfare.

Proof: When the subsidy is $s$, the amount the green firm has to spend on $\mathrm{R} \& \mathrm{D}$ in order to achieve a marginal cost $g$ becomes $(1-s) i(g-\bar{g})^{2}$. Thus, a subsidy reduces the effective $i$ for the green firm. It can have no effect in a tax regime (as long as $s<1$ which we assume), since any expenditure at all is sufficient to deter the firm from conducting $R \& D$. In a quota regime, it is clear from Proposition 2 that it can have an effect only if it moves the effective $i$ for the firm below the threshold $\frac{3}{2} \frac{\delta^{2}}{b \bar{q}^{2}}$. At this threshold value of $i$, the firm is indifferent between conducting $\mathrm{R} \& \mathrm{D}$ and not doing so. That is $\Pi(0)=\Pi(\bar{g})=0$. Therefore, its gross

profit if it conducts $\mathrm{R} \& \mathrm{D}, \pi(0)$ must equal $i \bar{g}^{2}$, the social cost of $\mathrm{R} \& \mathrm{D}$ at the threshold level of $i$.

Now welfare will be raised by inducing the firm to conduct R \& $\mathrm{D}$ if and only if $w(0)-$ $w(\bar{g})>i \bar{g}^{2}$, that is, if and only if

$$
w(0)-w(\bar{g})>\pi(0) .
$$

$\pi(0)$ is equal to the area of the rectangle $A D I H$ in Figure 5 . But this is greater than $w(0)-w(\bar{g})$ by 2.4.1. Thus in a quota regime, if a subsidy is effective, it must reduce welfare.

\section{The MODEL WITH INCREASING MARGINAL COST OF DIRTY ENERGY}

Since fossil fuels have heterogeneous extraction costs that depend on the location and quality of deposits, they can be expected to have an increasing marginal cost of extraction. Accordingly we now assume the supply curve of dirty energy has a positive slope. We show that it is possible for the tax regime to induce $\mathrm{R} \& \mathrm{D}$, and that a welfare improving $\mathrm{R} \& \mathrm{D}$ subsidy is possible under both tax and quota regimes.

\subsection{Structure of the MOdel}

We assume that

$$
\text { the marginal cost of producing } e_{d}=c e_{d}
$$

The supply curve of dirty energy implied by equation (3.1.1) can also be written as:

$$
S_{d}(P)=\frac{P}{c}
$$


Thus, $c$ denotes the slope of the dirty technology's marginal cost. Recall that the marginal benefit of energy is $a-b e$ while the marginal cost of dirty energy when there is an emissions tax of $t$ is $t+c e_{d}$.

Let

$$
P_{d}^{*}(t)=\frac{a c+b t}{b+c}
$$

denote the equilibrium price of dirty energy when there is no green energy produced and there is an emissions tax of $t$.

We assume that the initial marginal cost of the green technology $\bar{g}$ is too high for it to be socially optimal to have any production of green energy. (Later we show that the alternative assumption leads to qualitatively similar results).

\section{Assumption 3.1}

$$
P_{d}^{*}(t=\delta)<\bar{g}
$$

The equilibrium quantity of dirty energy when there is no green sector and there is an emissions tax of $t$ is

$$
e_{d}^{*}(t) \equiv S_{d}\left(P_{d}^{*}(t)-t\right)=\frac{a-t}{b+c} .
$$

The model under these assumptions is summarized in Figure 6 .

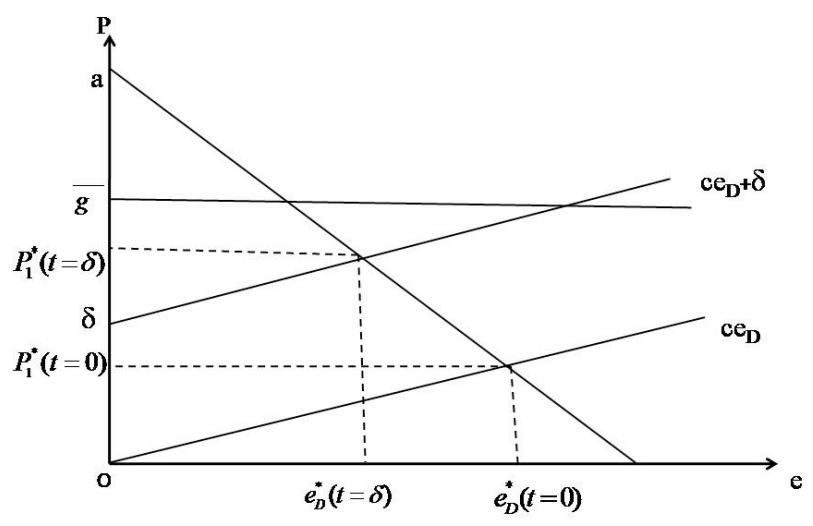

Figure 6: Diagrammatic representation of Assumptions 1 to 4

\subsection{Quota Regime}

As before, we solve the game by backward induction. 


\subsubsection{Response of firms given that $R \& \mathcal{E} D$ investment has been made and a quota chosen} by government

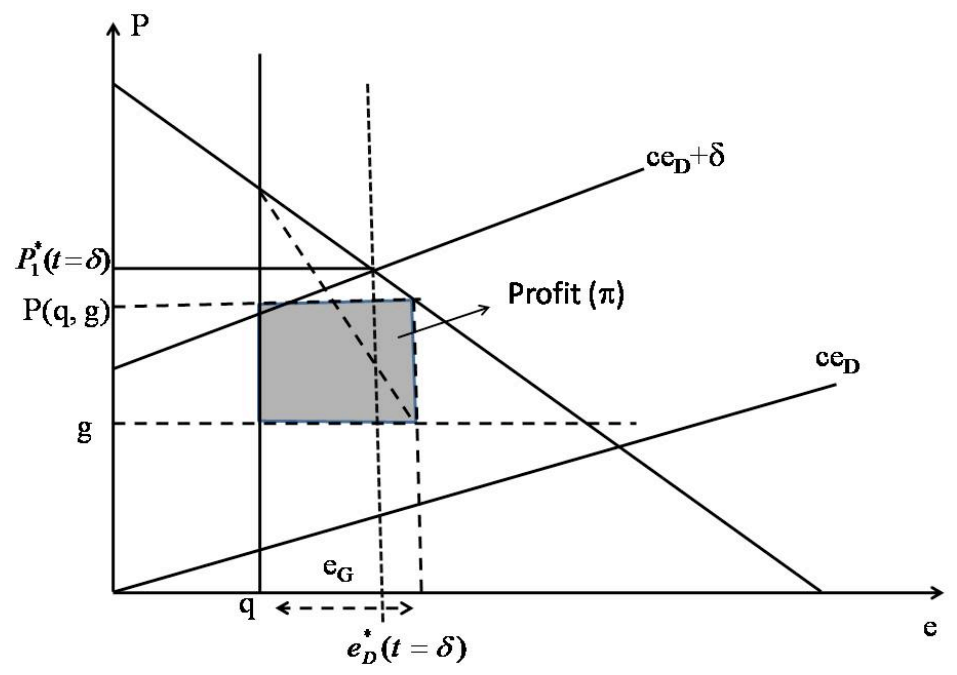

Figure 7: Choice of green energy output when $P_{d}^{*}(t=0) \leq g \leq P_{d}^{*}(t=\delta)$

If $g>P_{d}^{*}(t=\delta)$, it is clear that the optimal quota is $e_{d}^{*}(t=\delta)$ and the green firm is shut out of the market.

Now consider the case $P_{d}^{*}(t=0) \leq g \leq P_{d}^{*}(t=\delta)$. As in Section 2, the green firm chooses its output to maximize its profit given the residual demand curve for energy after the dirty sector has produced $q .{ }^{6}$ Thus, the green firm's optimization problem is identical to that in Section 2. So optimal green energy production, total energy production, the price of energy, and the gross profit of the green firm are given by (2.3.1), (2.3.2), (2.3.3) and (2.3.4) respectively. (Refer to figure 7).

Next, consider the case $g<P_{d}^{*}(t=0)$. It is straightforward to show that in the absence of government intervention, profit maximization by the green firm would lead to an energy price $P=\frac{1}{2}\left[P_{d}^{*}(t=0)+g\right]$ and dirty energy production $e_{d}=\frac{1}{2 c}\left[P_{d}^{*}(t=0)+g\right]$. To avoid a proliferation of cases, we assume below that the marginal damage $\delta$ from dirty energy is high enough that the government never finds it optimal to set a non-binding quota $q>e_{d}=\frac{1}{2 c}\left[P_{d}^{*}(t=0)+g\right]$. Hence, in this case also, optimal green energy production, total energy production, the price of energy, and the gross profit of the green firm are given by (2.3.1), (2.3.2), (2.3.3) and (2.3.4) respectively.

\footnotetext{
${ }^{6}$ It is clear that the quota must be binding on the dirty sector, since $g \geq P_{d}^{*}(t=0)$ and it cannot be optimal for the government to set $q \geq D(g)$.
} 
3.2.2 The government's choice of quota, after observing the green firm's choice of $g$ and taking the green firm's reaction function as given.

We have already noted that when $g>P_{d}^{*}(t=\delta)$, then the optimal quota is $e_{d}^{*}(t=\delta)$. When $0 \leq g \leq P_{d}^{*}(t=\delta)$, the gross welfare function is

$$
w(q, g)=a\left(\frac{a+b q-g}{2 b}\right)-\frac{b}{2}\left(\frac{a+b q-g}{2 b}\right)^{2}-\delta q-\frac{\delta q^{2}}{2}-g\left(\frac{a-b q-g}{2 b}\right)
$$

The marginal social benefit from tightening the quota is, as in Section 2, the reduction in social cost when dirty energy is replaced by green energy, while the marginal welfare loss arises from the reduction in net welfare from energy consumption. So the optimal quota satisfies

$$
c q+\delta-g=\frac{1}{2}\left[\frac{a-b q-g}{2}\right]
$$

provided it is not optimal to set a zero quota, which we assume. The required assumption, as in Section 2, is

\section{Assumption $3.2 a-4 \delta>0$}

For $g<P_{d}^{*}(t=0)$, we make the following assumption which ensures that it is optimal for the government to set a quota that is binding for the dirty sector ${ }^{7}$ :

Assumption $3.3 \frac{b-2 c}{2(b+c)} a-4 \delta<0$

Given assumption 3.2 and 3.3, it follows from 3.2.2 that the government's reaction function is:

$$
q(g)=\left\{\begin{array}{lll}
e_{d}^{*}(t=\delta) & \text { if } & g>P_{d}^{*}(t=\delta) \\
\frac{a+3 g-4 \delta}{b+4 c} & \text { if } & g \leq P_{d}^{*}(t=\delta)
\end{array}\right.
$$

As in Section 2 the optimal quota falls when $g$ falls.

There is an important respect in which this model differs from the model with a constant marginal cost of dirty energy. In the flat supply curve case, it was seen that for every $g<\delta$, the optimal choice of $q$ was such that $e(g, q)<D(\delta)$. To be precise, $e(g, q(g)$ was a increasing function of $g$ that is, $\frac{d e}{d g}>0$. However, with increasing marginal cost,

\footnotetext{
${ }^{7}$ This is proved in the Appendix A.
} 


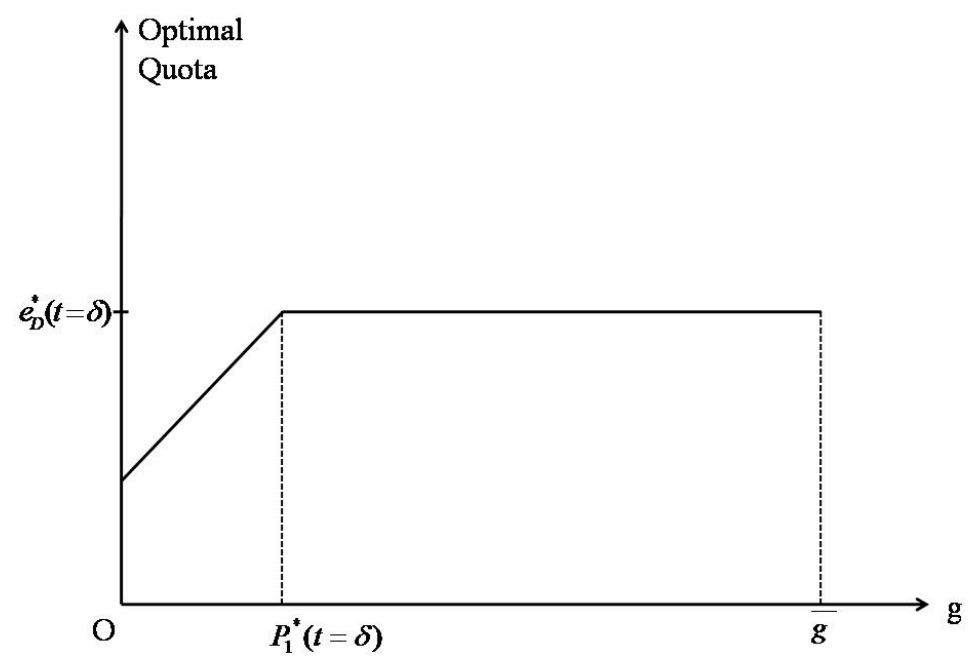

Figure 8: Government's reaction Function

$$
\begin{aligned}
\frac{d e}{d g} & =\frac{\partial e}{\partial g}+\frac{\partial e}{\partial q} \cdot \frac{d q}{d g} \\
& =-\frac{1}{2 b}+\frac{1}{2} \frac{3}{(b+4 c)} \\
& =\frac{(b-2 c)}{b(b+4 c)}
\end{aligned}
$$

Thus, if $c>\frac{b}{2}$, then energy consumption rises as $g$ falls. This has implications for welfare analysis and the role of an R \& D subsidy.

\subsubsection{Optimal choice of investment (and marginal cost) by green firm subject to the reaction function of government and it's own reaction function in period 2}

As before, the firm never chooses $g \in\left[P_{d}^{*}(t=\delta), \bar{g}\right)$. This is because while such cost reduction from $\bar{g}$ is costly, it does not allow the firm to operate in the market in the second period. In the range $\left[0, P_{d}^{*}(t=\delta)\right.$ ), the net profit function is (obtained by substituting the government's reaction function into the profit function (2.3.4) and subtracting the investment cost):

$$
\begin{aligned}
\Pi(g) & =\frac{4}{b(b+4 c)^{2}}[a c+b \delta-(b+c) g]^{2}-i(\bar{g}-g)^{2} \\
& =\frac{4(b+c)^{2}}{b(b+4 c)^{2}}\left[P_{d}^{*}(t=\delta)-g\right]^{2}-i(\bar{g}-g)^{2}
\end{aligned}
$$




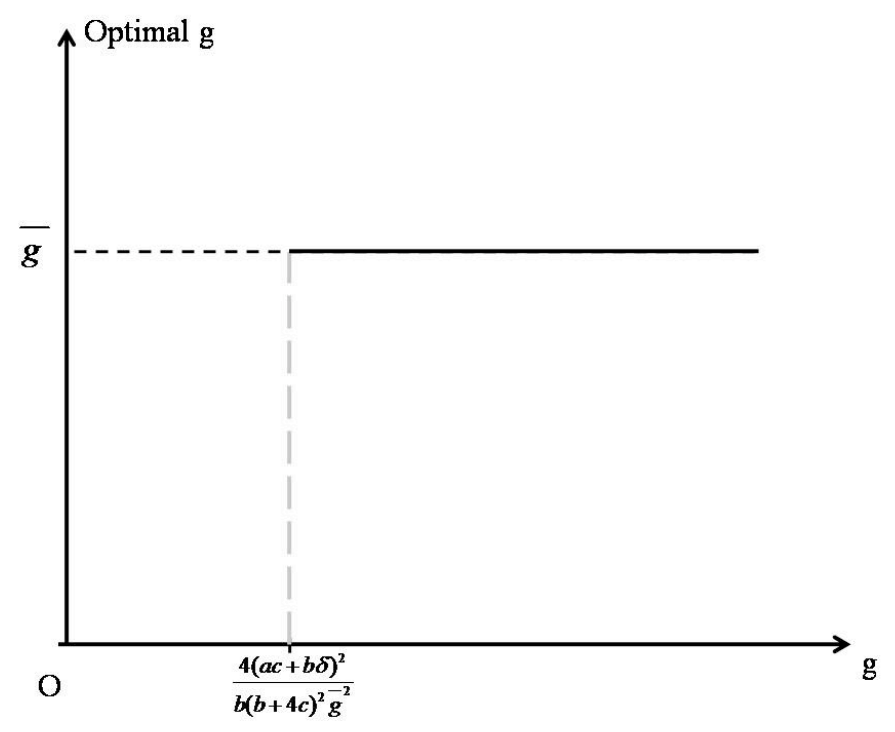

Figure 9: Optimal Choice of Marginal Cost

As before, the green firm's maximization problem has a corner solution (proof in the Appendix B):

$$
g= \begin{cases}0, & \text { if } \quad i \leq \frac{4(a c+b \delta)^{2}}{b(b+4 c)^{2} \bar{g}^{2}} \\ \bar{g}, & \text { if } \quad i \geq \frac{4(a c+b \delta)^{2}}{b(b+4 c)^{2} \bar{g}^{2}} .\end{cases}
$$

This is depicted in Figure 9.

\subsubsection{The Role of an $R \& D$ Subsidy}

We remarked above that total energy output will be greater when there is a green firm than in its absence if and only if the marginal cost of dirty energy is sufficiently steep relative

to the marginal benefit of energy, that is, $c>\frac{b}{2}$. If this is not the case, then for $i$ below the threshold, $g=0$ and the quota, energy output, and the energy price will be as depicted in Figure 10.

By an argument similar to the one made in 2.5 with reference to Figure 5 , we can conclude that an R \& D subsidy would be welfare-reducing if it had any effect.

On the other hand, if $c>\frac{b}{2}$, then for $i$ below the threshold, the situation would be as depicted in Figure 11.

$\pi(0)$ is given by the area of the rectangle AFED. Gross welfare when there is R \& D and $g=0$ is

$$
w(0)=a K B J+K F E D
$$




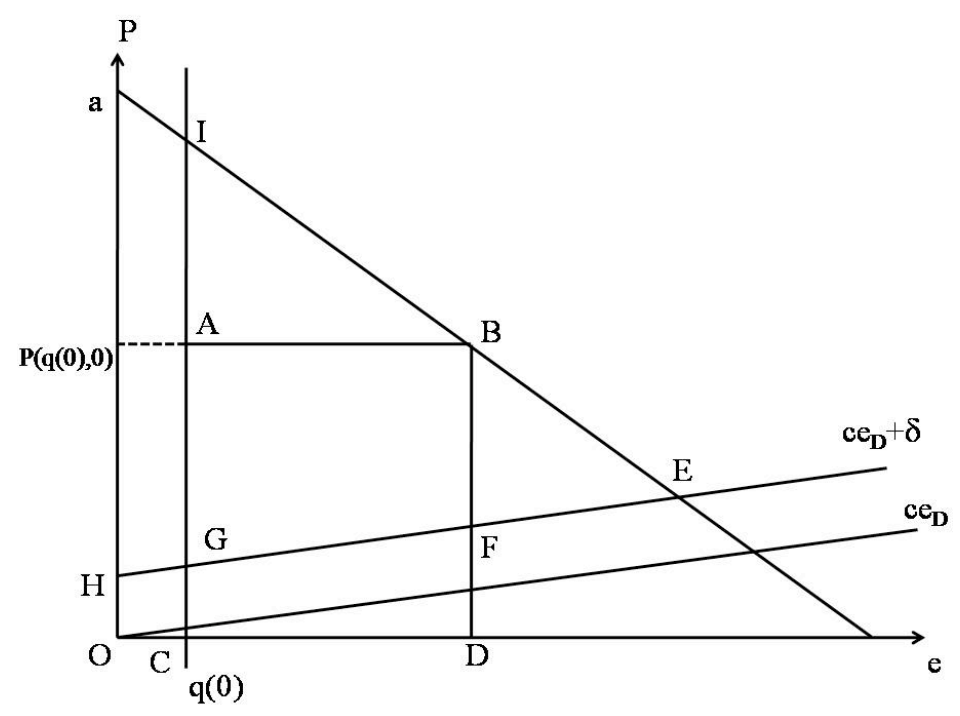

Figure 10: Case A: Role of Subsidy

If there is no $\mathrm{R} \& \mathrm{D}$, then

$$
w(\bar{g})=\triangle a I J .
$$

So the increase in welfare from conducting $\mathrm{R} \& \mathrm{D}$ minus the increase in profits from conducting $\mathrm{R} \& \mathrm{D}$ is

$$
\{w(0)-w(\bar{g})\}-\pi(0)=\triangle I F L-\triangle A L B .
$$

Now $\triangle L I F>\triangle A L B$ if and only if $c>\frac{5}{4} b$ (proof in the Appendix $\mathrm{C}$ ). At the threshold value of $i$, the increase in profit from $\mathrm{R} \& \mathrm{D}$ is zero. Thus, if $c<\frac{5}{4} b$, there can be no welfare improving subsidy. This argument has been summarized in proposition 5

Proposition 5 If $c<\frac{5}{4} b$, then there can be no welfare-improving subsidy to $R \& B$ in the quota regime. If $c>\frac{5}{4} b$, then an $R \& D$ subsidy can improve investment and welfare if the marginal cost of green energy is sufficiently sensitive to $R \& D$, that is for $i \in\left[\frac{4(a c+b \delta)^{2}}{b(b+4 c)^{2} \bar{g}^{2}}, \frac{3(a c+b \delta)^{2}}{2 b(b+c)(b+4 c) \bar{g}^{2}}\right]$.

\subsubsection{Relaxing assumption 3.1}

Suppose we relax assumption 3.1. We allow the initial marginal cost of green technology to be too high for it to be introduced in the absence of government policy intervention, but low enough for it to be socially optimal to have some green production of energy. The results of this changed situation can be summarized in: 


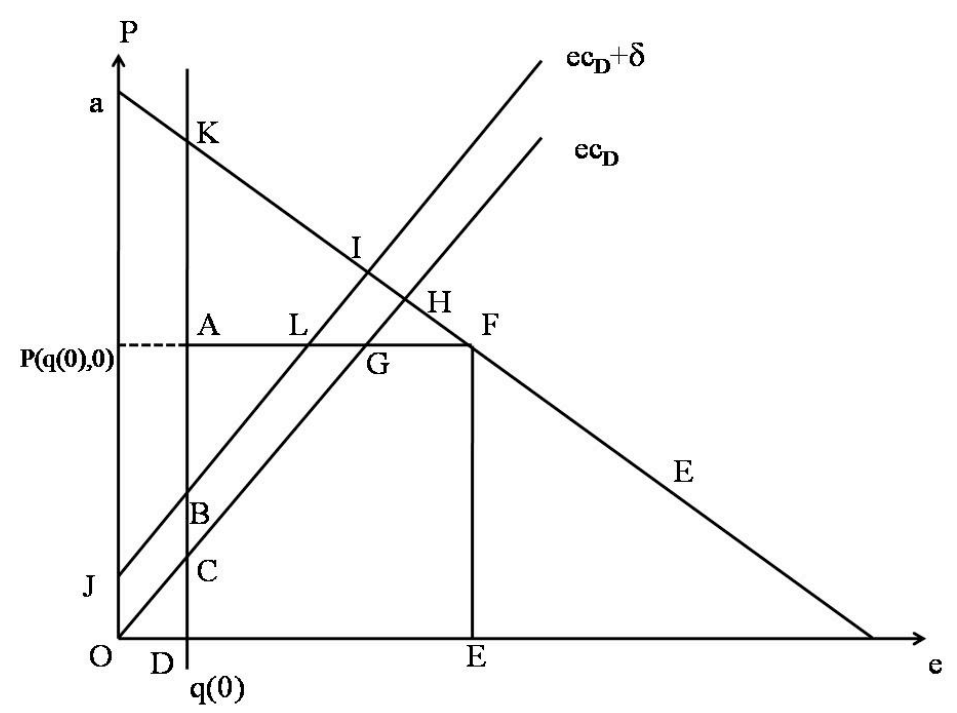

Figure 11: Case B: Role of Subsidy

Proposition 6 Let $P_{d}^{*}(t=0) \leq g \leq P_{d}^{*}(t=\delta)$. Then with all other assumptions of section 3 remaining unchanged, the quota regime induces the maximum possible $R \& D$ with $g=0$ provided that the marginal cost of green energy is sufficiently sensitive to $R \& D$ investment, that is, if (and only if) $i \leq \frac{4(b+c)(a c+b \delta)}{b(b+4 c)^{2} \bar{g}}$. For values of $i$ greater than $\frac{4(b+c)(a c+b \delta)}{b(b+4 c)^{2} \bar{g}}$, the optimal choice of $g$ by the green firm increases smoothly (at a decreasing rate) with $i$. The optimal choice of $g$ is strictly less than $\bar{g}$ for all finite values of $g$.

If $c<\frac{5}{4} b$, then there can be no welfare-improving subsidy to $R \& B$ in the quota regime. If $c>\frac{5}{4} b$, then an $R \mathscr{E} D$ subsidy can improve investment and welfare if $i \geq \frac{4(b+c)(a c+b \delta)}{b(b+4 c)^{2} \bar{g}}$.

Proof: In Appendix D.

\subsection{TAX REGIME}

As before, we solve the game by backward induction:

3.3.1 Response of firms given that investment has been made and a tax chosen by government.

In the last stage, the firm chooses its price $P$ to maximize its profit function

$$
\pi(g, t)=\left\{\begin{array}{lll}
\pi^{+}=(P-g) D(P), & \text { if } \quad P \in[g, t) \\
\pi^{++}=(P-g)\left[D(P)-S_{1}(P-t)\right], & \text { if } \quad P \in\left[t, P_{d}^{*}(t)\right]
\end{array}\right.
$$




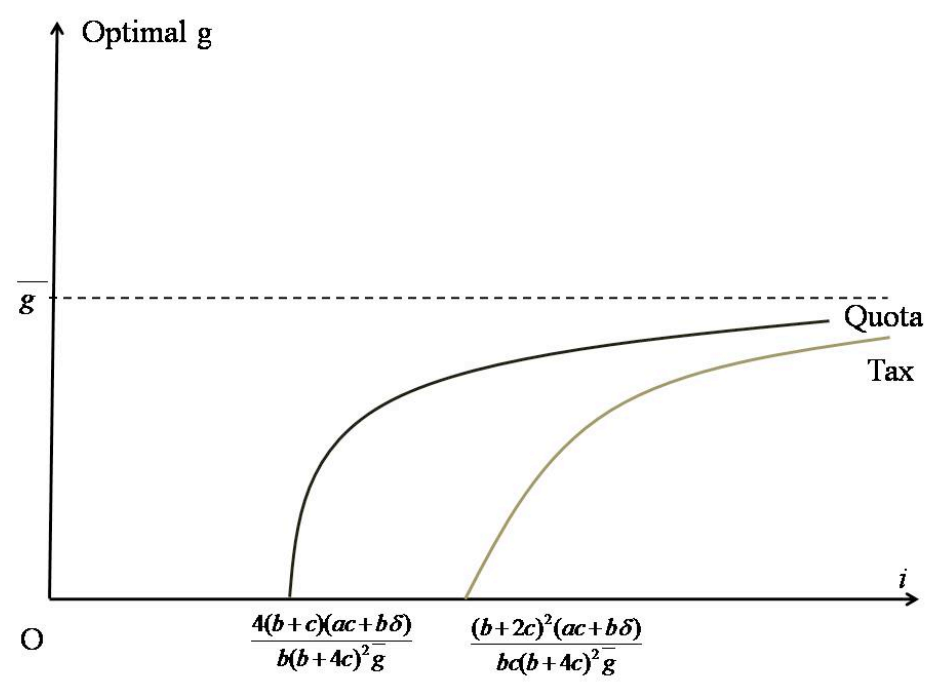

Figure 12: Optimal Choice of g when $P_{d}^{*}(t=0) \leq g \leq P_{d}^{*}(t=\delta)$

Suppose $g>P_{d}^{*}(t=\delta)$ so that the marginal cost of the green firm is greater than the marginal social cost of dirty energy at $e_{d}^{*}(t=\delta)$. It is clear that the optimal tax level is $\delta$ and the green firm is shut out of the market. The price of energy will be $P_{d}^{*}(t=\delta)$.

Now consider the case $g \in\left(P_{d}^{*}(t=0), P_{d}^{*}(t=\delta)\right]$. In this case, the price reaction function is as follows:

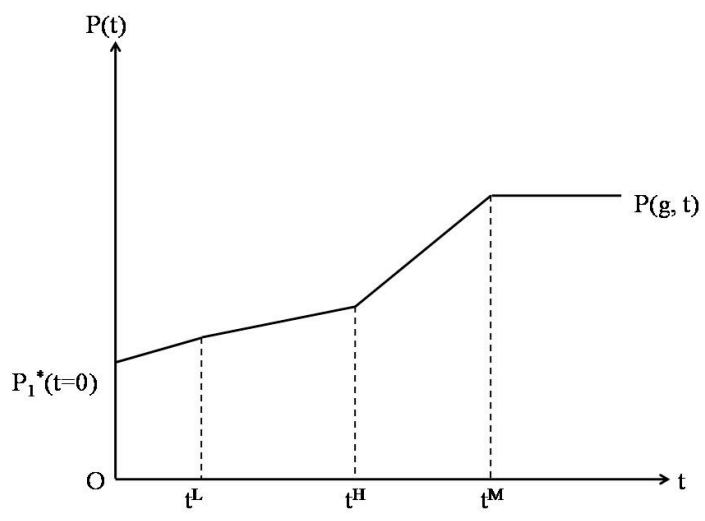

Figure 13: Price as a function of tax, for a particular marginal cost above $P_{d}^{*}(t)$

The government never chooses a tax lower than $t^{L}=\frac{(b+c) g-a c}{b}$, the highest tax level at which the green firm does not find it optimal to operate in the energy market. At the tax 
level $t^{L}$, the green firm's marginal cost is just equal to the post-tax price attained in its absence i.e. $P_{d}^{*}\left(t=t^{L}\right)$. Total energy produced is $e_{d}^{*}\left(t=t^{L}\right)$. For tax levels less than $t^{L}$, energy consumption (the whole of which is dirty energy) rises. However $e_{d}^{*}\left(t=t^{L}\right)>e_{d}^{*}(t=\delta)$ where $e_{d}^{*}(t=\delta)$ is the level of dirty energy produced at which the marginal social cost equals marginal social benefit. Thus increased production of dirty energy starting from a level greater than $e_{d}^{*}(t=\delta)$, ensures that the addition social costs of increased production outweigh the addition gains from increased production. Thus tax levels less than $t^{L}$ are never optimal.

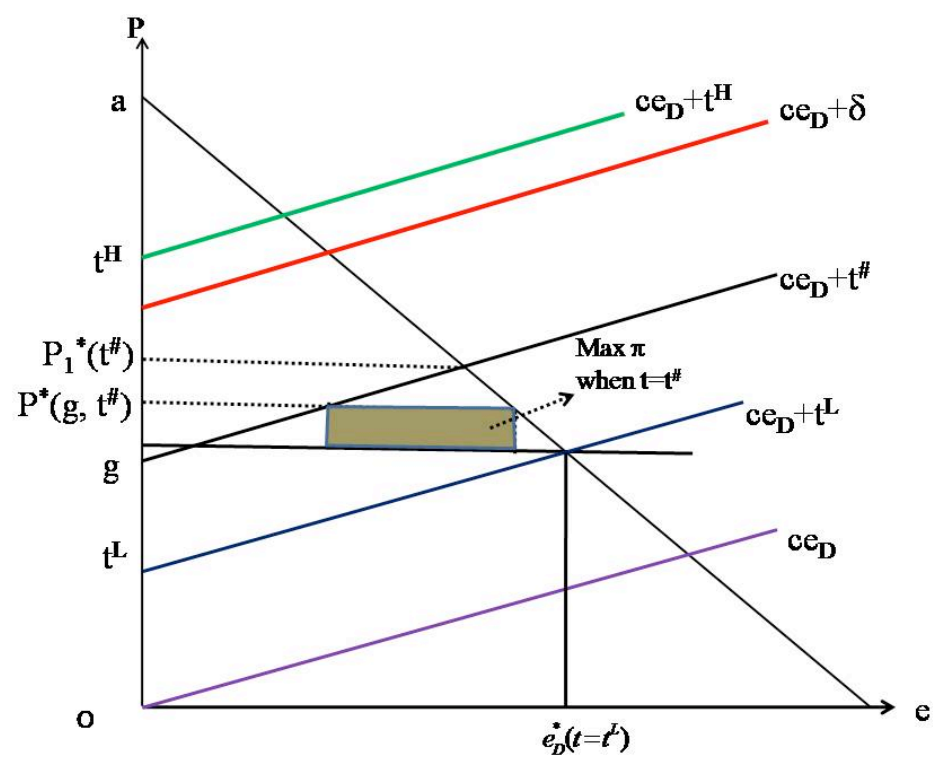

Figure 14: Diagram explaining the choice of prices under a tax regime

Suppose the government chooses a tax higher than $t^{L}$ but lower than $t^{H}$ where $t^{H}$ refers to the lowest possible tax level at which the green firm's profit maximizing level of price is such that the dirty firms are driven out of the market. This is denoted by $t^{\#}$ in Figure 14. Now the green firm has a role to play as the post-tax price attained in absence of the green firm is higher than $g$. To drive out the dirty sector completely, the green firm has to set the price marginally less than $t$. Since the tax is not very high, by choosing a price marginally less than $t$, the green firm enjoys the entire market (which is quite high given the low price) but the per unit margin is negative or positive but not very high. Thus the overall gain from driving out the dirty firms is either negative or positive but low. The firm does better by choosing a higher price optimally that reduces the demand it serves (and market share) but increases the per-unit gains. This optimal price is $P^{*}$, which is the equally weighted average of $g$ and $P_{d}^{*}(t)$. Profit is shown by the rectangle shaded in grey in Figure 14. As the tax 
moves higher towards $t^{H}$, the price set by the firm rises and the demand served by the dirty sector falls. This continues till $t^{H}$, the tax level at which the optimal price $P^{*}$ reaches a level at which the dirty industry is driven out of the market.

Suppose a tax greater than $t^{H}$ but less than $t^{M}$ is set, where $t^{M}$ is the lowest possible tax level at which the green firm can choose it's monopoly price. In this situation the green firm chooses $P=t$. By doing so it reduces demand but enhances the profit margin, but profit still increases as price is still below monopoly price. Once the tax level reaches $t^{M_{-}}$ a level that is high enough to ensure that even the choice of monopoly price can drive the dirty firms out, further increase in tax has no impact on price. The price stays unchanged at $P^{M}(g)$ as the firm can never earn more than what it does under monopoly.

However it should be noted that the government never raises the tax above $t^{H}$. Once the tax reaches $t^{H}$, the dirty sector is driven out. If the tax is increased further, the resultant rise in price reduces energy consumption but no gain is achieved from reduction in emissions as production of dirty energy has already reached zero. Thus if $g \in\left[P_{d}^{*}(t=0), P_{d}^{*}(t=\delta)\right)$, the relevant range from which the government chooses the tax is $\left[t^{L}, t^{H}\right]$.

Now suppose $g<P_{d}^{*}(t=0)$. Then $t^{L}<0$. We assume that zero is the minimum tax that can be set ${ }^{8}$. Taxes higher than $t^{H}$ are ruled out for reasons discussed earlier. The relevant range from which the government chooses a tax is $\left[0, t^{H}\right]$ for this case.

Summarizing the results obtained in this section, we can say that for any $g \geq P_{d}^{*}(t=\delta)$, $P(g, t(g))=P_{d}^{*}(t=\delta)$ and energy consumption is as follows: $e_{d}=e_{d}^{*}(t=\delta)$ and $e_{g}=0$.

For $g \in\left[0, P_{d}^{*}(t=\delta)\right)$

$$
\begin{gathered}
P(g, t(g))=\frac{1}{2}\left[g+P_{d}^{*}(t)\right. \\
e(g, t(g))=\frac{1}{2}\left[e_{d}^{*}(t)+D(g)\right] \\
e_{d}(g, t(g))=\frac{1}{2}\left[e_{d}^{*}(t)+S_{1}(g-t)\right] \\
e_{g}(g, t(g))=\frac{1}{2}\left[D(g)-S_{1}(g-t)\right]
\end{gathered}
$$

\footnotetext{
${ }^{8}$ Unlike the situation where $g>P_{d}^{*}(t=0)$, a subsidy to the dirty sector might be welfare improving as that reduces the loss arising out of the monopoly power of the green firm. However, we assume that once the government decides on as tax as its instrument, it sticks to that in future and a non-negative tax is then the only option available to the government.
} 


$$
\pi(g, t(g))=\frac{b+c}{4 b c}\left[P_{d}^{*}(t)-g\right]^{2}
$$

where $S_{1}(P)$ denotes the supply curve of the dirty sector in absence of tax.

\subsubsection{Optimal selection of $t$ by government, which observes green firm's choice of $g$ and} takes the green firm's reaction function as given.

It has already been argued that when $g>P_{d}^{*}(t=\delta)$, the optimal tax is equal to $\delta$. When $g \leq P_{d}^{*}(t=\delta)$, the government chooses a tax from the interval $\left(\min \left\{0, t^{L}\right\}, t^{H}\right]$ so as to maximize welfare.

The corner solution at $t^{L}$ is ruled out as an infinitesimally higher tax ensures first-order benefits from reduced emissions but the welfare loss from the fall in energy consumption is second-order. The corner solution at $t^{H}$ is attained only when $g \leq g^{H}$ where

$$
g^{H}=\frac{\delta(b+2 c)^{2}-a c^{2}}{(b+c)(b+3 c)}
$$

$g^{H}$ is the maximum cost level at which the optimal tax is such that green firm's optimal choice of price can drive out the dirty sector ${ }^{9}$. If $g>g^{H}$, we have an interior solution at a level of tax that satisfies:

$$
(a-b e) \frac{\partial e}{\partial t}=\left(\delta+c e_{d}\right) \frac{\partial e_{d}}{\partial t}+g \frac{\partial e_{g}}{\partial t}
$$

where

$$
\begin{gathered}
\frac{\partial e_{d}}{\partial t}=-\left(\frac{1}{2(b+c)}+\frac{1}{2 c}\right) \\
\frac{\partial e_{g}}{\partial t}=\frac{1}{2 c} \\
\frac{\partial e_{d}}{\partial t}+\frac{\partial e_{g}}{\partial t}=\frac{\partial e}{\partial t}
\end{gathered}
$$

where the marginal social benefit from higher tax (reduction in social cost when dirty energy is replaced by green energy) is equal to the marginal welfare loss (reduction in net welfare due to reduced energy consumption) ${ }^{10}$.

The intuition behind this non- monotonic shape of the tax curve ( $t$ as a function of $g$ ) is the following: $g>g^{H}$ implies that the difference between the MSC of dirty and green energy is not very large. Thus it is not optimal for the government to choose a high tax like $t^{H}(g)$ that will allow the green firm to drive out the dirty sector. Instead a lower tax is chosen, which allows both the sectors to survive. When $g$ falls substantially i.e. $g<g^{H}$, the

\footnotetext{
${ }^{9}$ Note that $g^{H}<\delta$.

${ }^{10}$ Proved in Appendix E.
} 
difference in the MSC of two firms becomes large to allow the choice of $t^{H}(g) .{ }^{11}$

Now for $g<g^{H}$, a reduction in marginal cost leads to a reduction in optimal tax. Thus the optimal choice of policy has a dampening effect on the profitability of the green energy firm. The situation is similar to the earlier model where the supply curve of dirty sector was flat. Since the objective of this model is to explore situations different from the earlier model, we rule out $g<g^{H}$ by making the following assumption ${ }^{12}$ :

Assumption $3.4 g^{H} \leq 0$ that is $\delta(b+2 c)^{2}<a c^{2}$

Given assumption 3.4, we can solve equation 3.3.6 to get the government's reaction function:

$$
t(g)= \begin{cases}\frac{a c-(b+c) g+2 \delta(b+2 c)}{b+4 c}, & \text { if } \quad g \in\left[0, P_{d}^{*}(t=\delta)\right] \\ \delta, & \text { if } g>P_{d}^{*}(t=\delta)\end{cases}
$$

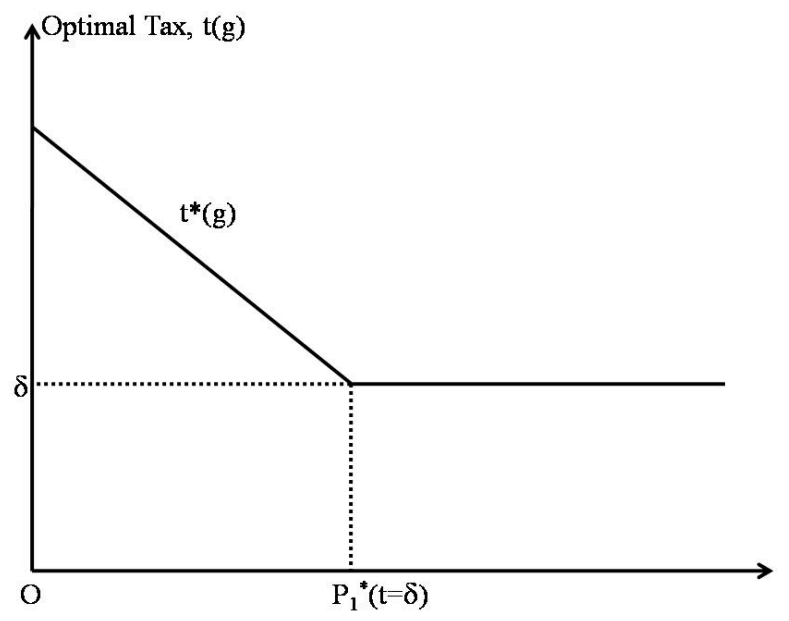

Figure 15: Government's reaction function: Tax as function of green firm's marginal cost

\subsubsection{Optimal choice of investment (and marginal cost) by the green firm subject to the reaction function of the government and it's own reaction function in period 2.}

As before, the firm never chooses $g \in\left[P_{d}^{*}(t=\delta), \bar{g}\right)$ as such investments do not allow firms to operate in the market in the second period. In the range $\left[0, P_{d}^{*}(g)\right)$, the net profit function

\footnotetext{
${ }^{11}$ Technical details are discussed in Appendix E.

${ }^{12}$ This assumption ensures that the slope of the supply curve is strictly positive. Thus we get results that are qualitatively different from Section 2.2. Unlike in Section 2.2, the tax ensures R \& D for low values of $i$.
} 
is (obtained by sequentially substituting the firm's second period reaction function and the government's reaction function into the profit function 3.3.5 and subtracting investment cost):

$$
\begin{aligned}
\Pi(g) & =\frac{b+c}{4 b c}\left[\frac{a c+b t}{b+c}-g\right]^{2}-i(\bar{g}-g)^{2} \\
\text { where, } \quad t & =\frac{a c-(b+c) g+2 \delta(b+2 c)}{b+4 c}
\end{aligned}
$$

Unlike section 2.2, the green firm's maximization problem can have solutions at either of the two corners: 0 or $\bar{g}$

$$
g= \begin{cases}0, & \text { if } \quad i \leq \frac{(b+2 c)^{2}(a c+b \delta)^{2}}{b c \bar{g}^{2}(b+c)(b+4 c)^{2}} \\ \bar{g}, & \text { if } \quad i \geq \frac{(b+2 c)^{2}(a c+b \delta)^{2}}{b c \bar{g}^{2}(b+c)(b+4 c)^{2}}\end{cases}
$$

Comparison between the optimal cost curves under the two regimes leads to the following propositions:

Proposition 7 For $i \in\left(\frac{4(a c+b \delta)^{2}}{b(b+4 c)^{2} \bar{g}^{2}}, \frac{(b+2 c)^{2}(a c+b \delta)^{2}}{b c \bar{g}^{2}(b+c)(b+4 c)^{2}}\right)$, a tax regime induces $R$ \& $D$ while a quota regime does not. For all other values of $i$, the two instruments are equivalent.

This is depicted in Figure 16. Proof of the above proposition (Proposition 7) discussed in Appendix F.

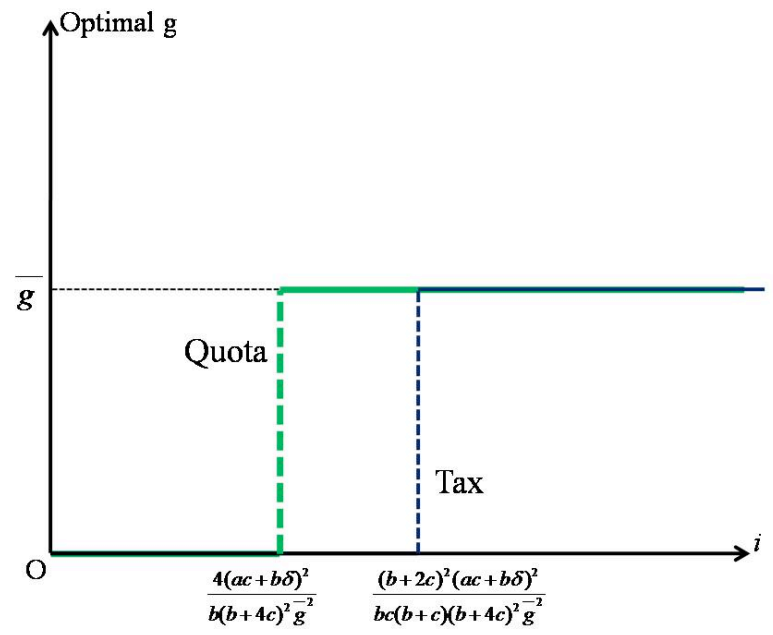

Figure 16: Optimal Cost as a function of $i$ in both tax and quota regimes 


\subsubsection{The role of an $R$ \& $D$ subsidy}

We know that at $i=\frac{(b+2 c)^{2}(a c+b \delta)^{2}}{b c \bar{g}^{2}(b+c)(b+4 c)^{2}}$,

$$
\begin{gathered}
\Pi(\bar{g})=\Pi(0) \\
\text { i.e. } \quad \pi(0)=i . \bar{g}^{2}
\end{gathered}
$$

By substituting $g=0$ in the optimal tax and price function, we get

$$
\begin{gathered}
t^{*}(0)=\frac{a c+2 \delta(b+2 c)}{(b+4 c)}>\delta \\
P\left(t^{*}(0), 0\right)=\frac{(a c+b \delta)(b+2 c)}{(b+c)(b+4 c)} \\
=\frac{(b+2 c)}{(b+4 c)} P_{d}^{*}(t=\delta) \\
<P_{d}^{*}(t=\delta)
\end{gathered}
$$

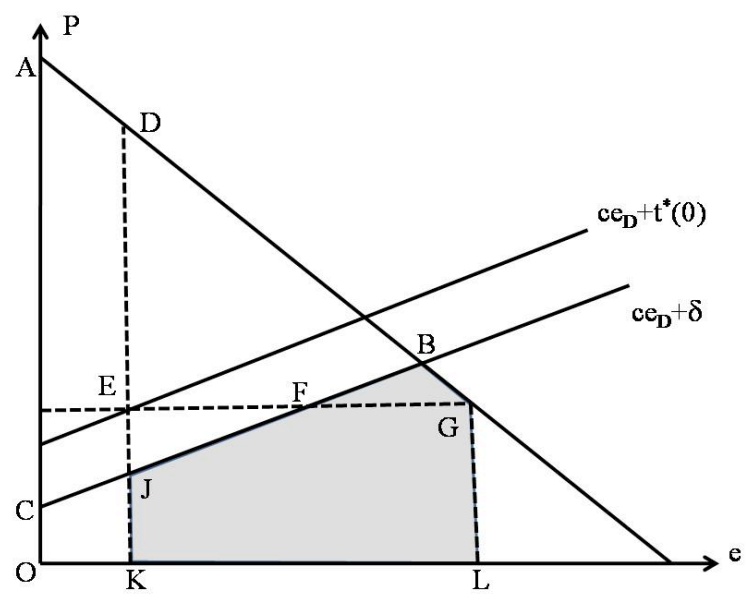

Figure 17: Diagram Explaining the role of subsidy

This situation is depicted in Figure 17. $\pi(0)$ is given by the rectangle $E G L K$. Gross welfare when there is $\mathrm{R} \& \mathrm{D}$ and $g=0$ is

$$
w(0)=A D J C+D K L G
$$

If there is no $\mathrm{R} \& \mathrm{D}, w(\bar{g})=\triangle A B C$. Therefore,

$$
w(0)-w(\bar{g})=J K L G B \quad(\text { Shaded in Grey })
$$


So the increase in welfare from conducting $\mathrm{R} \& \mathrm{D}$ minus the increase in profits from conducting R\& D is

$$
\{w(0)-w(\bar{g})\}-\pi(0)=\triangle F G B-\triangle E F J
$$

Now $\triangle F G B>\triangle E F J$ if and only if $4 c^{2}-b c-b^{2}>0$ i.e $c>\frac{1+\sqrt{17}}{8} b$. At the threshold value of $i$, the increase in profit from $\mathrm{R} \& \mathrm{D}$ is zero. Thus if $c<\frac{1+\sqrt{17}}{8} b$, there can be no welfare improving subsidy. Also note that $i=\frac{(b+3 c)(a c+b \delta)^{2}}{2 b c \bar{g}^{2}(b+c)(b+4 c)}$ is the maximum level of $i$ from which a subsidy can reduce $g$ from $\bar{g}$ to 0 and yet increase welfare ${ }^{13}$. Thus we can summarize the results of this subsection in

Proposition 8 If $c<\frac{1+\sqrt{17}}{8} b$, then a welfare-improving subsidy to $R \& D$ does not exist in the tax regime. If $c>\frac{1+\sqrt{17}}{8} b$, then an $R \& D$ subsidy can improve investment and welfare if $i \in\left[\frac{(b+2 c)^{2}(a c+b \delta)^{2}}{b c \bar{g}^{2}(b+c)(b+4 c)^{2}}, \frac{(b+3 c)(a c+b \delta)^{2}}{2 b c \bar{g}^{2}(b+c)(b+4 c)}\right]$

\subsubsection{Relaxing assumption 3.1}

Suppose we relax Assumption 3.1. We allow the initial marginal cost of the green technology $(\bar{g})$ to be too high for it to be introduced in the absence of government policy intervention, but low enough for it to be socially optimal to have some green production of energy. The results of this changed situation can be summarized in:

Proposition 9 Let $P_{d}^{*}(t=0) \leq \bar{g} \leq P_{d}^{*}(t=\delta)$. Then with all other assumptions of Section 3 remaining unchanged, the tax regime induces the maximum possible $R$ \& $D$ with $g=0$ provided that the marginal cost of green energy is sufficiently sensitive to $R \& D$ investment, that is, if (and only if) $i \leq \frac{(b+2 c)^{2}(a c+b \delta)}{b c \bar{g}(b+4 c)^{2}}$. For values of $i$ greater than $\frac{(b+2 c)^{2}(a c+b \delta)}{b c \bar{g}(b+4 c)^{2}}$, the optimal choice of $g$ by the green firm increases smoothly (at a decreasing rate) with $i$. The optimal choice of $g$ is strictly less than $\bar{g}$ for all values of $g$.

For $i>\frac{4(b+c)(a c+b \delta)}{b(b+4 c)^{2} \bar{g}}$, the tax regime induces more investment in $R \& D$ compared to the quota regime (Figure 12).

If $c<\frac{1+\sqrt{17}}{8} b$, then there can be no welfare-improving subsidy to $R \& D$ in the tax regime. If $c>\frac{1+\sqrt{17}}{8} b$, then an $R \& D$ subsidy can improve investment and welfare if $i \geq \frac{(b+2 c)^{2}(a c+b \delta)^{2}}{b c \bar{g}^{2}(b+c)(b+4 c)^{2}}$.

Proof: Proof discussed in Appendix H.

Thus, we see that the change in assumption $\bar{g}>P_{d}^{*}(t=\delta)$ does not change any of the earlier results qualitatively. A tax continues to induce more $\mathrm{R} \& \mathrm{D}$ than a quota. The only change is in the shape of the optimal $g$ curve.

\footnotetext{
${ }^{13}$ Proof in Appendix G.
} 


\subsection{Welfare Comparisons Between the two Regimes}

Proposition 10 When $c>\frac{1+\sqrt{17}}{8}$, the tax regime leads to higher welfare for all values of $i$ for which it ensures $g=0$. When $c<\frac{1+\sqrt{17}}{8}$, tax regime ensures higher welfare for $i<\frac{(b+3 c)(a c+b \delta)^{2}}{2 b c \bar{g}^{2}(b+c)(b+4 c)}$, quota regime lead to higher welfare for $i \in\left(\frac{(b+3 c)(a c+b \delta)^{2}}{2 b c \bar{g}^{2}(b+c)(b+4 c)}, \frac{(b+2 c)^{2}(a c+b \delta)^{2}}{b c \bar{g}^{2}(b+c)(b+4 c)^{2}}\right)$ and both regimes ensure equal welfare for $i>\frac{(b+2 c)^{2}(a c+b \delta)^{2}}{b c \bar{g}^{2}(b+c)(b+4 c)^{2}}$.

Proof: Proof discussed in Appendix I.

\section{INTRODUCING UNCERTAINTY}

Until now we have assumed that a social planner (government) is a social welfare maximizer. In addition to that, it is assumed that the social planner of the current period and the green energy firm believe with certainty that the social planner will act as a social welfare maximizer even after R \& D investment has been made. While such an assumption is quite weak when the supply curve of dirty energy is flat, it becomes stringent when we assume a positively sloped supply curve. When the supply curve is flat, the dirty firms never earn rents irrespective of the stringency of the climate policy adopted by the government. In such a situation, welfare maximization seems to be the only rational objective of a government. However a positively sloped supply means that dirty sector rents could be negatively related to the stringency of climate policy. Political economy models suggest that governments will attach some weight to firm rents while choosing policy. The weight that a future government assigns to firm rents is a parameter in its objective function. The current government and the green firm do not know the value of this parameter with certainty.

For simplicity, we assume a binary distribution parameter values. Let us assume that with probability $p$, the government in the second period acts as a benevolent social welfare maximizer and with probability $(1-p)$ it only cares about firm rents. Thus, we can say that in period 2 , the government chooses the welfare maximizing optimal policy with probability $p$ and with probability $1-p$ it chooses the business as usual policy, i.e. there is no climate policy.

Introduction of uncertainty in this way changes only the green firm's optimal investment problem. There is no change in the government's ex-post choice problem and the green firm's optimal output decision. We assume that all other assumptions of section 3 remain unchanged. 
In period 1 , the firm chooses $g$ so as to maximize the expected profit:

$$
\begin{aligned}
E[\Pi(g)] & =p[\pi(g)-I(g)]+(1-p)\left[\pi^{n}(g)-I(g)\right] \\
& =p \cdot \pi(g)+(1-p) \cdot \pi^{n}(g)-I(g)
\end{aligned}
$$

where $\pi$ is the profit under optimal climate policy, $\pi^{n}$ is the profit with no climate policy and $E$ denotes the expectation operator.

In a situation of no climate policy, a green firm with a marginal cost above $P_{d}^{*}(0)$ is shut out of the market (and hence the gross profit of the firm is zero). If $g<P_{d}^{*}(0)$, the green firm maximizes profit by choosing a price equal to the equally weighted average of $g$ and $P_{d}^{*}(0)$. So when $g \leq P_{d}^{*}(0)$, the price, output and profit are as follows:

$$
\begin{aligned}
P^{n}(g) & =\frac{1}{2}\left[g+P_{d}^{*}(0)\right] \\
& =\frac{1}{2}\left[\frac{a c}{b+c}+g\right] \\
e_{g}^{n}(g) & =\frac{1}{2}\left[D(g)-S_{1}(g)\right] \\
& =\frac{(b+c)}{2 b c}\left[\frac{a c}{b+c}-g\right] \\
\pi^{n}(g) & =[P(g)-g] e_{g}(g) \\
& =\frac{(b+c)}{4 b c}\left[\frac{a c}{b+c}-g\right]^{2}
\end{aligned}
$$

Substituting for $\pi(g)$ and $\pi^{n}(g)$ is equation 4.0.1, we get the expected net profit function:

$$
E[\Pi(g)]=\left\{\begin{array}{l}
p \cdot\left[\frac{4(b+c)^{2}}{b(b+4 c)^{2}}\left[P_{d}^{*}(\delta)-g\right]^{2}\right]+(1-p) \cdot\left[\frac{(b+c)}{4 b c}\left[P_{d}^{*}(0)-g\right]^{2}\right]-i(\bar{g}-g)^{2} \\
\quad \text { if } g \in\left[0, P_{d}^{*}(0)\right) \\
p \cdot\left[\frac{4(b+c)^{2}}{b(b+4 c)^{2}}\left[P_{d}^{*}(\delta)-g\right]^{2}\right]-i(\bar{g}-g)^{2} \\
\quad \text { if } g \in\left[P_{d}^{*}(0), P_{d}^{*}(\delta)\right) \\
-i(\bar{g}-g)^{2} \\
\quad \text { if } g \in\left[P_{d}^{*}(\delta), \bar{g}\right]
\end{array}\right.
$$

The green firm's maximization problem has a corner solution (proof in Appendix J):

$$
g= \begin{cases}0, & \text { if } i<\frac{1}{\bar{g}^{2}}\left[\frac{4 p(a c+b \delta)^{2}}{b(b+4 c)^{2}}+\frac{(1-p) a^{2} c^{2}}{4 b c(b+c)}\right] \\ \bar{g}, & \text { otherwise }\end{cases}
$$


We observe that as in the case with certainty, $g$ is a step function of $i$. Only the threshold at which the firm shifts from 0 to $\bar{g}$ has shifted down. The lower the value of $p$, lower is the cut-off at which this shift happens.

Now we study the role of an $\mathrm{R} \& \mathrm{D}$ subsidy in a situation with uncertainty. Here we consider the case where $c<\frac{5}{4} b$. This was the case in which a subsidy was always welfare reducing in an environment of certainty. The intent is to show that uncertainty can reverse this result.

At $i=\frac{1}{\bar{g}^{2}}\left[\frac{4 p(a c+b \delta)^{2}}{b(b+4 c)^{2}}+\frac{(1-p) a^{2} c^{2}}{4 b c(b+c)}\right]$

$$
E[\Pi(0)]>E[\Pi(\bar{g})]
$$

$$
\begin{aligned}
\text { or, } \quad p . \pi(0)+(1-p) \pi^{n}(0)-i \bar{g}^{2} & =0 \\
\text { or, } \quad p . \pi(0)+(1-p) \pi^{n}(0) & =i \bar{g}^{2}
\end{aligned}
$$

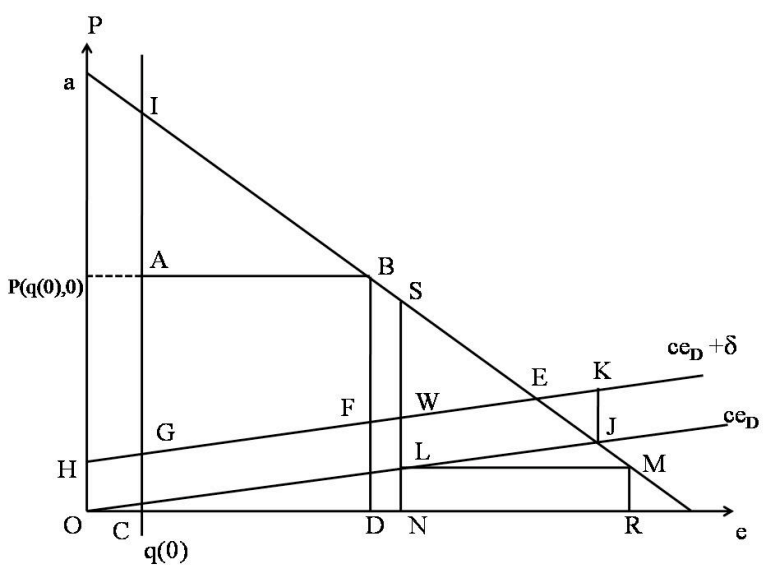

Figure 18: Subsidy analysis in quota regime with uncertainty

Now $E[\pi(0)]$ is given by the sum of $p$ times the area of $A B C D$ and $(1-p)$ times the area of $L N R M$. An R \& D subsidy can be welfare improving only if at $i=\frac{1}{\bar{g}^{2}}\left[\frac{4 p(a c+b \delta)^{2}}{b(b+4 c)^{2}}+\frac{(1-p) a^{2} c^{2}}{4 b c(b+c)}\right]$

$$
\Omega(p)=p[w(0)-w(\bar{g})]+(1-p)\left[w^{n}(0)-w^{n}(\bar{g})\right]-i \bar{g}^{2}>0
$$

where $w^{n}(g)$ denotes gross welfare as a function of $g$ when there is no policy.

For $p=1$,which is the case with no uncertainty, we know from the earlier section that $\Omega(p)=w(0)-w(\bar{g})-i \bar{g}^{2}<0$. For $p=0$, which is the situation with no climate policy, we know from Figure 18, 


$$
\begin{aligned}
p[w(0)-w(\bar{g})]+(1-p)\left[w^{n}(0)-w^{n}(\bar{g})\right] & =w^{n}(0)-w^{n}(\bar{g}) \\
& =[a S W H+S M R N]-[\triangle a E H-\triangle E K J] \\
& =W E M R N+\triangle E K J \\
& >\operatorname{LMRN} \\
& >\pi^{n}(0) \\
& =i . \bar{g}^{2} \quad \text { where } \quad i=\frac{1}{\bar{g}^{2}}\left[\frac{4 p(a c+b \delta)^{2}}{b(b+4 c)^{2}}+\frac{(1-p) a^{2} c^{2}}{4 b c(b+c)}\right]
\end{aligned}
$$

This implies that $\Omega(0)>0$. Since $\Omega(p)$ is a linear function of $p, \exists \hat{p} \in(0,1)$ such that $\Omega(p)$ is positive below $\hat{p}$ and negative thereafter. Using exactly similar reasoning, it can be shown that introduction of uncertainty expands the parameter space that supports welfare enhancing subsidy. The discussion in this section can be summarized in form of the following proposition:

Proposition 11 Suppose the parameters $b$ and $c$ are such that there can be no welfareimproving subsidy in the absence of uncertainty in a quota regime. If $p$ is the probability of having an ex-post optimal climate policy, there exists $\hat{p} \in(0,1)$ such that for $p<\hat{p}$, an $R$ \&D subsidy is welfare-improving for values of $i>\frac{1}{\bar{g}^{2}}\left[\frac{4 p(a c+b \delta)^{2}}{b(b+4 c)^{2}}+\frac{(1-p) a^{2} c^{2}}{4 b c(b+c)}\right]$. Similarly, the introduction of uncertainty expands the parameter space that supports a welfare-enhancing subsidy in a tax regime.

\section{Conclusion}

Technological innovation in the energy sector is clearly of central importance in any strategy to avoid too much climatic change. In this respect, the climate problem is distinct from many environmental problems in that it is probably more feasible to replace existing technologies entirely rather than find better ways to abate pollution using existing technologies. Accordingly, we have departed from most of the literature on innovation in environmental economics and modeled the incentive to conduct R \& D to lower the cost of such replacements. We have done this in a context in which the government is unable to commit to the future level of any policy instrument (although it is committed to the choice of instrument), an assumption that is necessary, given the fairly long delays to be expected between the decision to conduct $\mathrm{R} \& \mathrm{D}$ and the arrival of the resulting technology in the market. An important finding is that when the marginal cost curve of the existing dirty technology is flat, then an emissions tax is ineffective in inducing $\mathrm{R} \& \mathrm{D}$, but an emissions quota with tradeable permits can be effective (Propositions 1 and 2). In this case, under our maintained assumption of the perfect appropriability of the fruits of $R \& D$, an $R \& D$ subsidy was 
shown to be ineffective or welfare-reducing if effective (Proposition 4).

We noted that since existing carbon-emitting technologies are based on mineral deposits with heterogeneous extraction costs, there can be no doubt that the marginal cost of dirty energy is increasing in output, although we may not know how steeply. If the marginal cost curve of dirty energy is increasing sufficiently steeply, the results mentioned above are reversed. We have shown in Section 3 that both the emissions tax and the emissions quota can induce $\mathrm{R} \& \mathrm{D}$ and that an $\mathrm{R} \& \mathrm{D}$ subsidy can be a welfare-improving policy in conjunction with either an emissions tax or an emissions quota. Whether the tax or the quota regime gives rise to higher welfare under these circumstances depends on the sensitivity of the marginal cost of green energy to R \& D investment.

Since increasing marginal extraction costs give rise to rents, it is to be expected that rentiers will lobby to protect their rents. This introduces uncertainty about whether there will be any climate policy when the results of $\mathrm{R} \& \mathrm{D}$ are realized. It was shown in Section 4 that in the presence of such uncertainty, a subsidy to $\mathrm{R} \& \mathrm{D}$, because it takes effect in the present rather than the future, becomes a more attractive policy instrument.

What do these results imply for the choice of instruments in climate policy making? The likelihood that the marginal cost of dirty energy is increasing, together with the undoubted presence of uncertainty about whether there will be a meaningful climate policy in the future lead us to emphasize the results in Sections 3 and 4 that indicate a beneficial role for $\mathrm{R} \&$ $\mathrm{D}$ subsidies. Notice also that we did not model the possibility that the marginal cost of the green technology can fall below that of the dirty technology. In an earlier version of the paper we showed that in this case an $\mathrm{R} \& \mathrm{D}$ subsidy is welfare-improving if the effectiveness of $\mathrm{R} \& \mathrm{D}$ investment $1 / i$ is in an intermediate range. These considerations, together with the public good aspects of research and development that were not modeled in this paper, suggest that R \& D subsidies should form part of the policy mix. ${ }^{14}$

What about the choice between an emissions tax and a quota? Either could lead to greater welfare (assuming a sufficiently steep supply curve of dirty energy) depending on parameter values (Proposition 10). However, Propositions 7 and 9 tell us that a tax regime leads to a lower marginal cost of green energy than a quota regime, unless $i$ is small enough, in which case both induce the maximum possible $\mathrm{R} \& \mathrm{D}$. If we believe that the public good aspects of R \& D are sufficiently important, then these propositions make the emissions tax seem more attractive than the emissions quota with tradeable permits.

\footnotetext{
${ }^{14}$ (Acemoglu et al., 2010) explore the implications of positive externalities in R \& D in a dynamic setting.
} 


\section{REFERENCES}

Acemoglu, D., P. Aghion, L. Bursztyn, and D. Hemous (2010): "The environment and directed technical change," Fondazione Eni Enrico Mattei Research Paper Working Paper 93.2010.

Denicolo, V. (1999): "Pollution-reducing innovations under taxes or permits," Oxford Economic Papers, 51, 184-199.

Downing, P. B. And L. White (1986): "Innovation in Pollution Control," Journal of Environmental Economics and Management, 13, 18-29.

Fischer, C., I. W. H. PArry, And W. A. Pizer (2003): "Instrument choice for environmental protection when technological innovation is endogenous," Journal of Environmental Economics and Management, 45, 523-545.

FisheR, C. (2008): "Emissions pricing,spillovers, and public investment in environmentally friendly technologies," Energy Economics, 30, 487-502.

Jung, C., K. Krutilla, And R. Boyd (1996): "Incentives for advanced pollution abatement technology at the industry level: an evaluation of policy alternatives," Journal of Environmental Economics and Management, 30, 95-111.

Kneese, A. And C. Schulze (1975): "Pollution, prices and Public Policy," Brookings, Washington D.C.

Kolstad, C. D. (2010): "Regulatory Choice with Pollution and Innovation," NBER Working Paper No. 16303.

Laffont, J.-J. And J. Tirole (1996): "Pollution Permits and Environmental Innovation," Journal of Public Economics, 62, 127-140.

Marin, A. (1978): "The Choice of Efficient Pollution Policies: Technology and Economics in the Control of Sulphur Dioxide," Journal of Environmental Economics and Management, $5,44-62$.

Milliman, S. And R. Prince (1989): "Firm Incentives to Promote Technological change in Pollution Control," Journal of Environmental Economics and Management, 17, 247-265.

Montgomery, W. And A. Smith (2005): "Price, Quantity and Technological Strategies for Climate Change Policy," Working Paper, CRA International.

Requate, T. (2005): "Dynamic incentives by environmental policy instruments-a survey," Ecological Economics, 54, 175-195. 
Scotchmer, S. (2009): "Cap-and-Trade, Emissions Taxes, and Innovation," Working Paper, Dept. of Economics and School of Law, University of California, Berkeley.

Tinbergen, J. (1964): Economic Policy: Principles and Design, Amsterdam: North Holland. 


\section{APPENDICES}

\section{A Appendix FOR SECTION 3.2.2: \\ DERIVATION OF THE GOVERNMENT'S REACTION FUNCTION}

Differentiating Equation 3.2.1 with respect to $q$, we get

$$
\begin{gathered}
\frac{\partial w}{\partial q}=\frac{a}{4}-\frac{b q}{4}+\frac{3 g}{4}-\delta-c q \\
\left.\frac{\partial w}{\partial q}\right|_{q=0}=\frac{a}{4}+\frac{3 g}{4}-\delta
\end{gathered}
$$

To rule out corner solution at $q=0: a+3 g-4 \delta>0 \quad \forall g \geq 0 \Rightarrow a-4 \delta \geq 0$. This is Assumption 3.2. For $P_{d}^{*}(t=\delta) \geq g \geq P_{d}^{*}(t=0)$, the upper bound on the quota is $e_{d}^{*}(t=\delta)$.

$$
\begin{aligned}
\left.\frac{d W}{d q}\right|_{e_{d}^{*}(t=\delta)} & =\frac{a}{4}-\frac{b}{4} \frac{a-\delta}{b+c}+\frac{3}{4} g-\delta-c \frac{a-\delta}{b+c} \\
& =\frac{3}{4}\left[g-P_{d}^{*}(t=\delta)\right]<0
\end{aligned}
$$

For $g<P_{d}^{*}(t=0)$, the upper bound on the quota is the emission level achieved in the absence of a climate policy that is $q^{F}(g)$.

$$
\begin{aligned}
\left.\frac{d W}{d q}\right|_{q^{F}(g)} & =\frac{a}{4}+\frac{3 g}{4}-\delta-\left(\frac{b}{4}+c\right) \frac{1}{2 c}\left[\frac{a c}{b+c}+g\right] \\
& =\left(\frac{a}{4}-\delta-\frac{a(b+4 c)}{8(b+c)}-\frac{g}{8 c}(b-2 c)\right.
\end{aligned}
$$

If $b>2 c,\left.\frac{d W}{d q}\right|_{q^{F}(g)}$ is decreasing in $g$. To ensure that the quota is below $q^{F}(g)$ for all values of $g$, we need $\left.\frac{d W}{d q}\right|_{q^{F}(g)}$ evaluated at $g=0$ to be negative, that is, $\frac{b-2 c}{2(b+c)} a-4 \delta<0$. This is Assumption 3.3.

If $b<2 c,\left.\frac{d W}{d q}\right|_{q^{F}(g)}$ is increasing in $g$. To ensure that the quota is below $q^{F}(g)$ for all values of $g$, we need $\left.\frac{d W}{d q}\right|_{q^{F}(g)}$ evaluated at $g=P_{d}^{*}(t=0)$ to be negative, which is always true. Note that when $b<2 c$, the inequality in Assumption 3.3 is satisfied. 


\section{B APPENDIX FOR SECTION 3.2.3: \\ THE GREEN FIRM'S CHOICE OF $g$ HAS A CORNER SOLUTION IN THE QUOTA REGIME}

Differentiating Equation 3.2.4 with respect to $g$,

$$
\begin{gathered}
\frac{d \Pi}{d g}=-\frac{8(b+c)}{b(b+4 c)^{2}}\left[P_{1}^{*}(\delta)-g\right]+2 i(\bar{g}-g) \\
\left.\frac{d \Pi}{d g}\right|_{P_{1}^{*}(\delta)}=2 i\left(\bar{g}-P_{1}^{*}(\delta)\right)>0
\end{gathered}
$$

Now suppose the net profit curve is concave in the range $\left[0, P_{1}^{*}(\delta)\right)$. Given inequality (B.1), $P_{1}^{*}(\delta)$ maximizes net profit in this range. We know that net profit is negative at $P_{1}^{*}(\delta)$. Thus $\bar{g}$ is the global optimum when the profit function (3.2.4) is concave.

If the net profit curve is convex in the range $\left[0, P_{1}^{*}(\delta)\right.$ ), there are two candidates for optimum in the range $\left[0, P_{1}^{*}(\delta)\right): 0$ and $P_{1}^{*}(\delta)$. We know that net profit is negative at $P_{1}^{*}(\delta)$. Thus $\bar{g}$ and 0 are the two candidates for global optimum.

We know that net profit is zero when $g=\bar{g}$. The net profit at $g=0$ is as follows:

$$
\Pi(0)=\frac{4(a c+b \delta)^{2}}{b(b+4 c)^{2}}-i \bar{g}^{2}
$$

The firm chooses $g=0$ if $\Pi(0) \geq 0$ and $\bar{g}$ otherwise.

$$
i=\frac{4(a c+b \delta)^{2}}{b(b+4 c)^{2} \bar{g}^{2}}
$$

is the level of $i$ at which the firm is indifferent between choosing 0 and $\bar{g}$. Below this threshold, the firm chooses 0 and $\bar{g}$ otherwise.

\section{APPEndiX FOR SECTION 3.2.4:}

DERIVATION OF CONDITIONS FOR A WELFARE IMPROVING SUBSIDY IN THE QUOTA REGIME

Here we show that $\triangle L I F>\triangle A L B$ (in Figure 11) implies $c>\frac{5}{4} b$. Note

$$
P(q(g), g)=\frac{2(a c+b \delta)-(b-2 c) g}{b+4 c}
$$


Consider Figure 11. This figure corresponds to the situation where $b<2 c$.

$$
\begin{aligned}
M S C_{1}(q(0)) & =c \cdot\left\{\frac{a-4 \delta}{b+4 c}\right\}+\delta \\
& =\frac{a c+b \delta}{b+4 c} \\
& =\frac{1}{2} P(q(0), 0)
\end{aligned}
$$

where $M S C_{1}(q(0))$ is the marginal social cost of producing $q(0)$ of energy, using the dirty technology.

$$
P_{d}^{*}(\delta)-P(q(0), 0)=\frac{(2 c-b)(a c+b \delta)}{(b+c)(b+4 c)}>0
$$

$$
\text { Area of } \begin{aligned}
\triangle A L B & =\frac{1}{2} A L \cdot A B \\
& =\frac{1}{2}\left[P(q(0), 0)-M S C_{1}(q(0))\right] \cdot\left[S_{1}(P(q(0), 0)-\delta)-q(0)\right] \\
& =\frac{1}{2 c}\left(\frac{a c+b \delta}{b+4 \delta}\right)^{2}
\end{aligned}
$$

Area of $\triangle I F L=\frac{1}{2} F L \cdot[$ Perpendicular distance from vertex I]

$$
\begin{aligned}
& =\frac{1}{2}\left[D(P(q(0), 0))-S_{1}(P(q(0), 0)-\delta)\right] \cdot\left[P_{d}^{*}(\delta)-P(q(0), 0)\right] \\
& =\frac{(a c+b \delta)^{2}(2 c-b)^{2}}{2 b c(b+c)(b+4 c)^{2}}
\end{aligned}
$$

Therefore, $\triangle L I F>\triangle A L B$ if $b<\frac{4}{5} c$. Thus if $c<\frac{5}{4} b$, there can be no welfare-improving subsidy.

If $c>\frac{5}{4} b$, then

$$
\begin{gathered}
\{w(0)-w(\bar{g})\}-\pi(0)>0 \\
\text { or, } w(0)-i \cdot \bar{g}^{2}>w(\bar{g}) \quad \text { where } \quad i=\frac{4(a c+b \delta)^{2}}{b(b+4 c)^{2} \bar{g}^{2}}
\end{gathered}
$$

Thus at the right hand neighborhood of $\frac{4(a c+b \delta)^{2}}{b(b+4 c)^{2} \bar{g}^{2}}$, even an infinitesimal subsidy can increase both welfare and investment. Now,

$$
\begin{aligned}
w(0)-w(\bar{g}) & =B D E F \\
& =A F E D+\triangle I F L-\triangle A L B \\
& =\frac{3(a c+b \delta)^{2}}{2 b(b+c)(b+4 c)}
\end{aligned}
$$


Thus $\frac{3(a c+b \delta)^{2}}{2 b(b+c)(b+4 c) \bar{g}^{2}}$ is the highest level of $i$ from which a subsidy that ensures $g=0$ is welfare improving.

\section{Appendix for section 3.2.5: Proof of Proposition 6}

The firm chooses $g \in[0, \bar{g}]$ to maximize net profit which is given by Equation (3.2.4).

$$
\begin{gathered}
\text { FOC: } \quad \frac{d \Pi}{d g}=-\frac{8(b+c)}{b(b+4 c)^{2}}\left[P_{d}^{*}(\delta)-g\right]+2 i(\bar{g}-g) \\
\text { SOC: } \quad \frac{d^{2} \Pi}{d g^{2}}=\frac{8(b+c)^{2}}{b(b+4 c)^{2}}-2 i
\end{gathered}
$$

From the FOC, it is evident that the net profit curve is negatively sloped at $g=\bar{g}$ and hence $\bar{g}$ can never be optimum. The net profit curve is convex that is $\frac{d^{2} \Pi}{d g^{2}}>0$ for

$$
i<\frac{4(b+c)^{2}}{b(b+4 c)^{2}}
$$

while the net profit curve is negatively sloped at $g=0$ that is $\left.\frac{d \Pi}{d g}\right|_{g=0}$ if

$$
i<\frac{4(b+c)(a c+b \delta)}{b(b+4 c)^{2} \bar{g}}
$$

Equating the FOC to 0, we get the interior solution as

$$
g=\frac{b i \bar{g}(b+4 c)^{2}-4(b+c)(a c+b \delta)}{b i(b+4 c)^{2}-4(b+c)^{2}}
$$

Thus the optimal choice of $g$ is given by:

$$
g= \begin{cases}0, & \text { if } \quad i \leq \frac{4(b+c)(a c+b \delta)}{b(b+4 c)^{2} \bar{g}} \\ \frac{b i \bar{g}(b+4 c)^{2}-4(b+c)(a c+b \delta)}{b i(b+4 c)^{2}-4(b+c)^{2}}, & \text { if } \quad i \geq \frac{4(b+c)(a c+b \delta)}{b(b+4 c)^{2} \bar{g}}\end{cases}
$$

If $s$ is the rate of subsidy on investment, the net profit function is:

$$
\begin{gathered}
\Pi(g)=\frac{4}{b(b+4 c)^{2}}[a c+b \delta-(b+c) g]^{2}-i(1-s)(\bar{g}-g)^{2} \\
=\frac{4(b+c)^{2}}{b(b+4 c)^{2}}\left[P_{d}^{*}(\delta)-g\right]^{2}-(1-s) i(\bar{g}-g)^{2} \\
\text { FOC: } \quad \frac{d \Pi}{d g}=0
\end{gathered}
$$




$$
\text { or, } \quad-\frac{8(b+c)}{b(b+4 c)^{2}}\left[P_{d}^{*}(\delta)-g\right]+2(1-s) i(\bar{g}-g)=0
$$

Initially $s=0$ and we assume that the optimum $g$ is greater than zero ${ }^{15}$. Differentiating (D.3), with respect to $s$, we get:

$$
\frac{\partial g}{\partial s}=\frac{2 b i(b+4 c)^{2}(\bar{g}-g)}{8(b+c)^{2}-2 b i(1-s)(b+4 c)^{2}}<0
$$

as

$$
\frac{\partial^{2} \Pi}{d g^{2}}=\frac{8(b+c)^{2}}{b(b+4 c)^{2}}-2 i(1-s)<0
$$

Now, social welfare as a function of $g(s)$ is as follows:

$$
w(g(s))=Y+a . e-\frac{b}{2} e^{2}-\frac{c}{2} e_{d}^{2}-\delta e_{d}-g e_{g}
$$

where:

$$
\begin{aligned}
& e_{d}=q \\
& e_{g}=\frac{a-b q-g}{2 b} \\
& e=e_{d}+e_{g} \\
& q=\frac{a+3 g-4 \delta}{b+4 c} \\
&\left.\frac{d W}{d g}=\frac{3[(b+c) g}{b(b+4 c)}-(a c+b \delta)\right] \\
&
\end{aligned}
$$

Substituting from equation (D.3),

$$
\begin{aligned}
\left.\frac{d W}{d g}\right|_{s=0} & =\frac{[(b+c) g-(a c+b \delta)]}{b(b+4 c)}\left[\frac{8(b+c)}{b+4 c}-3\right] \\
& =\frac{[(b+c) g-(a c+b \delta)]}{b(b+4 c)^{2}}[5 b-4 c]
\end{aligned}
$$

A marginal subsidy is welfare improving if $c>\frac{5}{4} b$ and welfare reducing if $c<\frac{5}{4} b$

Now holding $i$ constant at a particular level greater than $\frac{4(b+c)(a c+b \delta)}{b(b+4 c)^{2} \bar{g}}, W(g, i)$ is a smooth and continuous function of $g$. Now,

$$
\begin{aligned}
\left.\frac{d W}{d g}\right|_{g=\bar{g}} & =\frac{3((b+c) g-(a c+b \delta))}{b(b+4 c)}<0 \quad \text { as } \quad \bar{g}<P_{d}^{*}(\delta) \\
\frac{d^{2} W}{d g^{2}} & =\frac{3(b+c)}{b(b+4 c)}-2 i
\end{aligned}
$$

\footnotetext{
${ }^{15}$ If initial $g$ is zero, then a subsidy is ineffective as marginal cost is already at it's lowest possible level
} 
$W(h, i)$ is globally concave or convex depending on the value of $i$ and is negatively sloped at $\bar{g}$. If a marginal subsidy is welfare reducing, it means that $W(g, i)$ curve is positively sloped in the neighborhood of the no-subsidy equilibrium value of $g$. Given the above two observations, the curve should be positively sloped for all values of $g$ to the left of no-subsidy equilibrium value of $g$. Thus if a marginal subsidy is welfare reducing, so is a subsidy of higher magnitude.

\section{E APPENDIX FOR SECTION 3.3.2:}

Derivation of Government's Reaction Function under Tax

\section{REGIME}

Expanding Equation 3.3.6, we get:

$$
\begin{gathered}
\frac{\partial w}{\partial t}=\frac{a c+2 \delta(b+2 c)-(b+c) g-(b+4 d) t}{4 c(b+c)} \\
\left.\frac{\partial w}{\partial t}\right|_{t_{L}}=\frac{(2 b+c)(a c+b \delta-(b+c) g)}{2 b c(b+c)}>0 \quad \text { as } \quad g<P_{d}^{*}(\delta) \\
\left.\frac{\partial w}{\partial t}\right|_{0}=\frac{a c+2 \delta(b+2 c)-(b+c) g}{4 c(b+c)}>0 \quad \text { as } \quad g<P_{d}^{*}(\delta)+\frac{(b+4 c) \delta}{b+c}
\end{gathered}
$$

Thus corner solutions at $\min \left\{0, t^{L}\right\}$ is ruled out.

$$
\left.\frac{\partial w}{\partial t}\right|_{t^{H}}=\frac{\delta(b+2 c)^{2}-a c^{2}-(b+c)(b+3 c) g}{2 c(b+c)(b+2 c)}
$$

The corner solution at $t^{H}$ is attained only when $\left.\frac{\partial w}{\partial t}\right|_{t^{H}}>0$ that is $g<g^{H}=\frac{\delta(b+2 c)^{2}-a c^{2}}{(b+c)(b+3 c)}$.

If $g>g^{H}$, we solve the first order condition, by equating E.1 to zero, to get an interior solution at $t^{*}(g)$ where

$$
t^{*}=\frac{a c-(b+c) g+2 \delta(b+2 c)}{b+4 c}
$$

\section{F Appendix for section 3.3.3: Proof of Proposition 7}

Differentiating Equation 3.3.8 with respect to $g$,

$$
\begin{gathered}
\frac{d \Pi(g)}{d g}=\frac{(b+c)}{2 b c}\left[\frac{a c+b t}{b+c}-g\right]\left[\frac{b}{b+c} \frac{d t(g)}{d g}-1\right]+2 i(\bar{g}-g) \\
\text { where } \frac{d t(g)}{d g}=-\frac{b+c}{b+4 c}
\end{gathered}
$$


Substituting, we get:

$$
\begin{gathered}
\frac{d \Pi(g)}{d g}=-\frac{2(b+c)(b+2 c)^{2}}{b c(b+4 c)^{2}}\left[P_{d}^{*}(t=\delta)-g\right]+2 i(\bar{g}-g) \\
\frac{d^{2} \Pi(g)}{d g^{2}}=\frac{2(b+c)(b+2 c)^{2}}{b c(b+4 c)^{2}}-2 i
\end{gathered}
$$

Note that:

$$
\left.\frac{d \Pi(g)}{d g}\right|_{g=P_{d}^{*}(t=\delta)}>0
$$

If the net profit curve is concave, inequality (F.4) ensures that in the range $\left[0, P_{d}^{*}(g)\right]$, $g=P_{d}^{*}(g)$ gives the lowest net loss. Thus the only choice of $g$ that can give non-negative net profits is $\bar{g}$. Thus $\bar{g}$ is the global optimum.

If the net profit curve is convex, then in the range $\left[0, P_{d}^{*}(g)\right]$, there are two candidates for optimum: 0 and $P_{d}^{*}(g)$. We know that at $g=P_{d}^{*}(g)$, net profit is negative. Thus we are left with just two candidates for global optimum : 0 and $\bar{g}$.

$\bar{g}$ is the optimal choice if $i$ is greater than the level of $i$ at which:

$$
\begin{aligned}
\Pi(0) & =0 \\
\text { or, } \quad i & =\frac{(b+2 c)^{2}(a c+b \delta)^{2}}{b c \bar{g}^{2}(b+c)(b+4 c)^{2}}
\end{aligned}
$$

The green firm's maximization problem can have solutions at either of the two corners: 0 or $\bar{g}$. The optimal cost function is :

$$
g= \begin{cases}0, & \text { if } \quad i \leq \frac{(b+2 c)^{2}(a c+b \delta)^{2}}{b c \bar{g}^{2}(b+c)(b+4 c)^{2}} \\ \bar{g}, & \text { if } \quad i \geq \frac{(b+2 c)^{2}(a c+b \delta)^{2}}{b c \bar{g}^{2}(b+c)(b+4 c)^{2}}\end{cases}
$$

Let $i^{T}$ and $i^{Q}$ be the threshold levels at which the optimal cost curves in tax and quota regime jump from $g=0$ to $g=\bar{g}$.

$$
\begin{gathered}
i^{T}=\frac{(b+2 c)^{2}(a c+b \delta)^{2}}{b c \bar{g}^{2}(b+c)(b+4 c)^{2}} \\
i^{Q}=\frac{4(a c+b \delta)^{2}}{b(b+4 c)^{2} \bar{g}^{2}} \\
\text { Thus, } \frac{i^{T}}{i^{Q}}=\frac{(b+2 c)^{2}}{4 c(b+c)}>1
\end{gathered}
$$

Thus, the optimal cost curves have the shape given in Figure 16 . 


\section{G Appendix FOR SECTION 3.3.4:}

\section{DERIVATION OF CONDITIONS FOR A WELFARE IMPROVING SUBSIDY IN TAX REGIME}

We show that for $\triangle F G B>\triangle E F J$ (in Figure 17), we need $4 c^{2}-b c-b^{2}>0$. Consider Figure 17.

$$
\begin{aligned}
\triangle E F J & =\frac{1}{2} \cdot E J \cdot E F \\
& =\frac{1}{2} \cdot\left[P^{*}\left(t^{*}(0), 0\right)-\left(\delta+c e_{d}\left(t^{*}(0), 0\right)\right)\right] \cdot\left[\frac{P^{*}\left(t^{*}(0), 0\right)-\delta}{c}-e_{d}\left(t^{*}(0), 0\right)\right] \\
& =\frac{1}{2} \cdot \frac{a c+b \delta}{b+4 c} \cdot \frac{a c+b \delta}{c(b+4 c)} \\
& =\frac{1}{2 c}\left(\frac{a c+b \delta}{b+4 c}\right)^{2} \\
\triangle F G B & =\frac{1}{2} \cdot F G \cdot[\text { Perpendicular distance of edge } F G \text { from } B] \\
& =\frac{1}{2} \cdot\left[D\left(P^{*}\left(t^{*}(0), 0\right)\right)-\frac{P^{*}\left(t^{*}(0), 0\right)-\delta}{c}\right] \cdot\left[P_{d}^{*}(t=\delta)-P^{*}\left(t^{*}(0), 0\right)\right] \\
& =\frac{1}{2} \cdot \frac{2(a c+b \delta)}{b(b+4 c)} \cdot \frac{2 c(a c+b \delta)}{(b+c)(b+4 c)} \\
& =\frac{2 c}{b(b+c)}\left(\frac{a c+b \delta}{b+4 c}\right)^{2}
\end{aligned}
$$

Therefore, $\triangle F G B-\triangle E F J=\left(\frac{a c+b \delta}{b+4 c}\right)^{2} \cdot\left[\frac{2 c}{b(b+c)}-\frac{1}{2 c}\right]$

Thus, $\triangle F G B-\triangle E F J$ is positive if $4 c^{2}-b c-b^{2}>0$ that is $c>\frac{1+\sqrt{17}}{8} b$.

Thus we can have two cases:

- Case A: $4 c^{2}-b c-b^{2}<0$

In this case, $w(0)-w(\bar{g})<\pi(0)=\left\{\frac{(b+2 c)^{2}(a c+b \delta)^{2}}{b c \bar{g}^{2}(b+c)(b+4 c)^{2}}\right\} \bar{g}^{2}<i \bar{g}^{2}$ for all $i>\frac{(b+2 c)^{2}(a c+b \delta)^{2}}{b c \bar{g}^{2}(b+c)(b+4 c)^{2}}$.

Thus, $w(0)-i \bar{g}^{2}<w(\bar{g})$ for all $i>\frac{(b+2 c)^{2}(a c+b \delta)^{2}}{b c \bar{g}^{2}(b+c)(b+4 c)^{2}}$

- Case B: $4 c^{2}-b c-b^{2}>0$

In this case, $w(0)-w(\bar{g})>\pi(0)=\frac{(b+2 c)^{2}(a c+b \delta)^{2}}{b c \bar{g}^{2}(b+c)(b+4 c)^{2}}$. 
Now,

$$
\begin{aligned}
w(0)-w(\bar{g}) & =\text { Area of } E K L G+\text { Area of } \triangle F G B-\text { Area of } \triangle E F J \\
& =P\left(t^{*}(0), 0\right) \cdot e_{g}\left(t^{*}(0), 0\right)+\text { Area of } \triangle F G B-\text { Area of } \triangle E F J \\
& =\frac{(a c+b \delta)^{2}(b+2 c)^{2}}{b c(b+c)(b+4 c)^{2}}+\left[\left(\frac{a c+b \delta}{b+4 c}\right)^{2} \cdot\left[\frac{2 c}{b(b+c)}-\frac{1}{2 c}\right]\right] \\
& =\frac{(b+3 c)(a c+b \delta)^{2}}{2 b c(b+c)(b+4 c)} \\
& =>\pi(0) \text { as } 4 c^{2}-b(b+c)>0
\end{aligned}
$$

Thus, $\frac{(b+3 c)(a c+b \delta)^{2}}{2 b c \bar{g}^{2}(b+c)(b+4 c)}$ is the highest level of $i$ from which a subsidy that encourages R \& D can be welfare improving.

\section{H Appendix for section 3.3.5: Proof of Proposition 9}

The firm chooses $g \in[0, \bar{g}]$ to maximize net profit which is given by 3.3.8. The first and second order conditions are obtained from F.2 and F.2 respectively. Substituting $g=\bar{g}$ in F.2, we get $\left.\frac{d \Pi(g)}{d g}\right|_{\bar{g}}<0$. The net profit curve is convex if

$$
i<\frac{(b+c)(b+2 c)^{2}}{b c(b+4 c)^{2}}
$$

and the curve is negatively sloped at $g=0$ if

$$
i<\frac{(a c+b \delta)(b+2 c)^{2}}{b c \bar{g}(b+4 c)^{2}}
$$

Thus if $i<\frac{(a c+b \delta)(b+2 c)^{2}}{b c \bar{g}(b+4 c)^{2}}$, optimal $g$ is 0 . For values of $i$ greater than this cut-off, we have an interior solution that is obtained by settng the FOC to zero. The interior solution is:

$$
g=\frac{b c i \bar{g}(b+4 c)^{2}-4(b+2 c)^{2}(a c+b \delta)}{b c i(b+4 c)^{2}-(b+2 c)^{2}(b+c)}
$$

If $s$ is the rate of subsidy on investment, the net profit function is:

$$
\begin{aligned}
\Pi(g) & =\frac{(b+2 c)^{2}}{b c(b+c)(b+4 c)^{2}}[a c+b \delta-(b+c) g]^{2}-i(1-s)(\bar{g}-g)^{2} \\
& =\frac{(b+2 c)^{2}(b+d)}{b c(b+4 c)^{2}}\left[P_{d}^{*}(\delta)-g\right]^{2}-(1-s) i(\bar{g}-g)^{2} \\
\frac{d \Pi}{d g} & =-\frac{2(b+2 c)^{2}}{b c(b+4 c)^{2}}[a c+b \delta-(b+c) g]+2(1-s) i(\bar{g}-g)
\end{aligned}
$$


Initially $s=0$ and we assume that the optimum $g$ is greater than zero ${ }^{16}$. Differentiating the equation $\frac{d \Pi}{d g}=0$, with respect to $s$, we get:

$$
\begin{gathered}
\frac{\partial g}{\partial s}=\frac{i(\bar{g}-g)}{\frac{(b+c)(b+2 c)^{2}}{b c(b+4 c)^{2}}-(1-s) i}<0 \\
\text { as } \frac{d^{2} \Pi}{d g^{2}}=2 \frac{(b+c)(b+2 c)^{2}}{b c(b+4 c)^{2}}-2(1-s) i<0
\end{gathered}
$$

Now, social welfare as a function of $g(s)$ is as follows:

$$
w(g(s))=Y+a . e-\frac{b}{2} e^{2}-\frac{c}{2} e_{d}^{2}-\delta e_{d}-g e_{g}
$$

where: $e_{d}, e_{g}$ and $e$ are functions of $g$ obtained by substituting the government's optimal choice of tax in Equations: 3.3.2, 3.3.4 and 3.3.3.

$$
\frac{d W}{d g}=\frac{-(b+3 c)(a c+b \delta-(b+c) g)}{b c(b+4 c)}+2 i(\bar{g}-g)
$$

Substituting from the first order conditon ( (H.2)),

$$
\left.\frac{d W}{d g}\right|_{s=0}=\frac{a c+b \delta-(b+c) g}{b c(b+4 c)^{2}}\left(b^{2}+b c-4 c^{2}\right)
$$

A marginal subsidy is welfare improving if $c>\frac{1+\sqrt{17}}{8} b$ and welfare reducing if $c<\frac{1+\sqrt{17}}{8} b$ Now holding $i$ constant at a particular level greater than $\frac{(a c+b \delta)(b+2 c)^{2}}{b c \bar{g}(b+4 c)^{2}}, W(g, i)$ is a smooth and continuous function of $g$. Now,

$$
\begin{aligned}
\left.\frac{d W}{d g}\right|_{g=\bar{g}} & =\frac{-(b+3 c)(a c+b \delta-(b+c) \bar{g})}{b c(b+4 c)}<0 \\
\frac{d^{2} W}{d g^{2}} & =\frac{(b+3 c)(b+c)}{b c(b+4 c)}-2 i
\end{aligned}
$$

$W(h, i)$ is globally concave or convex depending on the value of $i$ and is negatively sloped at $\bar{g}$. If a marginal subsidy is welfare reducing, it means that $W(g, i)$ curve is positively sloped in the neighborhood of the no-subsidy equilibrium value of $g$. Given the above two observations, the curve should be positively sloped for all values of $g$ to the left of no-subsidy equilibrium value of $g$. Thus if a marginal subsidy is welfare reducing, so is a higher amount of subsidy.

\footnotetext{
${ }^{16}$ If initial $g$ is zero, then a subsidy is ineffective as marginal cost is already at it's lowest possible level
} 


\section{Appendix for section 3.4: Proof of Proposition 10}

As $\bar{g}>P_{d}^{*}(\delta)$, the optimal cost curves are step functions in both regimes, as depicted in 16.

For $i>\frac{(b+2 c)^{2}(a c+b \delta)^{2}}{b c \bar{g}^{2}(b+c)(b+4 c)^{2}}$, that is when there is no $\mathrm{R} \& \mathrm{D}$ in both regimes, welfare is equal to $\triangle A B C$ (in Figure 17 ) in both regimes.

For $i<\frac{4(a c+b \delta)^{2}}{b(b+4 c)^{2} \bar{g}^{2}}$, that is when $g=0$ in both the regimes, a tax regime provides higher welfare than a quota regime. Since the choice of $g$ is same in both regimes, the $\mathrm{R} \& \mathrm{D}$ cost is equal and hence comparing gross welfare is sufficient to make net welfare comparisons.

When $g=0$, optimal quota is given by $q(0)=\frac{a-4 \delta}{b+4 c}$. Substituting $q=q(0)$ and $g=0$ in the gross welfare function we get

$$
\begin{aligned}
\left.w(g=0)\right|_{\text {Quota }} & =a\left(\frac{a+b \frac{a-4 \delta}{b+4 c}}{2 b}\right)-\frac{b}{2}\left(\frac{a+b \frac{a-4 \delta}{b+4 c}}{2 b}\right)^{2}-\delta\left(\frac{a-4 \delta}{b+4 c}\right)-\frac{c}{2}\left(\frac{a-4 \delta}{b+4 c}\right)^{2} \\
& =\frac{a^{2}(b+3 c)-2 b \delta(a-2 \delta)}{2 b(b+4 c)}
\end{aligned}
$$

When $g=0$, optimal tax is given by $t(0)=\frac{a c+2 \delta(b+2 c)}{b+4 c}$. Substituting $t=t(0)$ and $g=0$, we obtain:

$$
\begin{aligned}
e(g=0) & =\frac{1}{2}\left[\frac{a-t(0)}{b+c}+\frac{a-0}{b}\right] \\
& =\frac{a b^{2}+4 a b c+2 a c^{2}-b^{2} \delta-2 b c \delta}{b(b+c)(b+4 c)} \\
e_{d}(g=0) & =\frac{1}{2}\left[\frac{a-t(0)}{b+c}+\frac{0-t(0)}{c}\right] \\
& =\frac{a c^{2}-b^{2} \delta-4 b c \delta-4 c^{2} d}{c(b+c)(b+4 c)}
\end{aligned}
$$

Substituting $e=e(g=0)$ and $e_{d}=e_{d}(g=0)$ in the gross welfare function, we get:

$$
\begin{aligned}
\left.w(g=0)\right|_{\text {Tax }} & =a e(g=0)-\frac{b}{2} e(g=0)^{2}-\delta e_{d}(g=0)-\frac{c}{2} e_{d}(g=0)^{2} \\
& =\frac{a^{2} b^{2} c+5 a^{2} b c^{2}+3 a^{2} c^{3}-2 a b c^{2} \delta+b^{3} \delta^{2}+4 b^{2} c \delta^{2}+4 b c^{2} \delta^{2}}{2 b c(b+c)(b+4 c)}
\end{aligned}
$$

Now,

$$
\left.w(g=0)\right|_{\text {Quota }}-\left.w(g=0)\right|_{\text {Tax }}=-\frac{(a c+b \delta)^{2}}{2 c(b+c)(b+4 c)}<0
$$

It follows that $\left.W(g=0)\right|_{\text {Quota }}<\left.W(g=0)\right|_{\text {Tax }}$. 
Now we consider the interior range of $i$ i.e. $\frac{4(a c+b \delta)^{2}}{b(b+4 c)^{2} \bar{g}^{2}}<i<\frac{(b+2 c)^{2}(a c+b \delta)^{2}}{b c \bar{g}^{2}(b+c)(b+4 c)^{2}}$. We consider two cases:

- Case (a): $c>\frac{1+\sqrt{17}}{8}$ From earlier discussions we know that a investment tax that changes optimal choice of $g$ from 0 to $\bar{g}$ is welfare reducing in this case. Thus for any $i$ in the interval $\left[\frac{4(a c+b \delta)^{2}}{b(b+4 c)^{2} \bar{g}^{2}}, \frac{(b+2 c)^{2}(a c+b \delta)^{2}}{b c \bar{g}^{2}(b+c)(b+4 c)^{2}}\right], g=0$ ensures higher net welfare than $g=\bar{g}$. Moreover, we know that both regimes give equal welfare for $g=\bar{g}$. Thus in this interval of $i$, a tax regime ensures higher net welfare than a quota regime.

- Case (b): $c<\frac{1+\sqrt{17}}{8}$ At $i=\frac{(b+2 c)^{2}(a c+b \delta)^{2}}{b c \bar{g}^{2}(b+c)(b+4 c)^{2}}$, a marginal investment tax that changes optimal choice of $g$ from 0 to $\bar{g}$ is welfare improving in this case. $\frac{w(0)-w(\bar{g})}{\bar{g}^{2}}=\frac{(b+3 c)(a c+b \delta)^{2}}{2 b c \bar{g}^{2}(b+c)(b+4 c)}$ is the minimum value of $i$, from which a tax can improve welfare.

Suppose, $\frac{(b+3 c)(a c+b \delta)^{2}}{2 b c \bar{g}^{2}(b+c)(b+4 c)}<\frac{4(a c+b \delta)^{2}}{b(b+4 c)^{2} \bar{g}^{2}}$. This implies

$$
\begin{aligned}
\frac{(b+3 c)}{2 c(b+c)} & <\frac{4}{(b+4 c)} \\
\text { or }(b+3 c)(b+4 c) & <8 c(b+c) \\
\text { or } 4 c^{2}-b c+b^{2} & <0
\end{aligned}
$$

This inequality cannot be satisfied by any real and positive value of $b$ and $c$. Thus, $\frac{(b+3 c)(a c+b \delta)^{2}}{2 b c \bar{g}^{2}(b+c)(b+4 c)}>\frac{4(a c+b \delta)^{2}}{b(b+4 c)^{2} \bar{g}^{2}}$.

Thus for $i<\frac{(b+3 c)(a c+b \delta)^{2}}{2 b c \bar{g}^{2}(b+c)(b+4 c)}$, the tax regime ensures higher welfare, where as for $i>$ $\frac{(b+3 c)(a c+b \delta)^{2}}{2 b c \bar{g}^{2}(b+c)(b+4 c)}$, the quota regime ensures higher welfare.

\section{J Appendix For Section 4: Proof of Proposition 11}

If $g \in\left[P_{d}^{*}(\delta), \bar{g}\right]$, the firm makes net loss equal to the magnitude of investment, even when optimal quota is chosen. This hold true even after introduction of uncertainty (substituting $\pi(g)=0$ and $\pi^{n}=0$ in Equation (4.0.1)). Note that $E\left[\Pi\left(P_{d}^{*}(\delta)\right)\right]=-I(\delta)<0$. Since choosing $g>P_{d}^{*}(t=\delta)$ is ruled out, the choice of $g$ has to be from $\left[0, P_{d}^{*}(\delta)\right) \bigcup\{\bar{g}\}$.

In the range $\left[P_{d}^{*}(0), P_{d}^{*}(\delta)\right)$, the expected net profit function is:

$$
E[\Pi(g)]=p . \pi(g)-I(g)
$$

Using the logic used in the case with certainty, we can argue that no value of $g$ above $P_{d}^{*}(0)$ can be optimum. This is because

$$
E^{\prime}\left[\Pi\left(g=P_{d}^{*}(t=\delta)\right)\right]>0
$$


ensuring that there cannot be an interior solution from $\left[P_{d}^{*}(0), P_{d}^{*}(\delta)\right)$, irrespective of the curvature of expected net profit curve. Thus the global equilibrium must always be from the set $\left[0, P_{d}^{*}(0)\right] \bigcup\{\bar{g}\}$.

In the range $\left[0, P_{d}^{*}(0)\right]$,

$$
\begin{aligned}
E[\Pi(g)]= & p \cdot \pi(g)+(1-p) \pi^{n}(g)-I(g) \\
= & \frac{4 p}{b(b+4 c)^{2}}(a c+b \delta-(b+c) g)^{2} \\
& +\frac{(1-p)}{4 b c(b+c)}(a c-(b+c) g)^{2}-i(\bar{g}-g)^{2}
\end{aligned}
$$

The first and second derivatives with respect to $g$ is:

$$
\begin{aligned}
\frac{d E[\Pi(g)]}{d g} & =-\frac{8 p(b+c)}{b(b+4 c)^{2}}(a c+b \delta-(b+c) g)-\frac{(1-p)}{2 b c}(a c-(b+c) g)+2 i(\bar{g}-g) \\
\frac{d^{2} e[\Pi(g)]}{d g^{2}} & =\frac{8 p(b+c)^{2}}{(b+4 c)^{2}}+\frac{(1-p)(b+c)}{2 b c}-2 i
\end{aligned}
$$

The expected profit curve in this range is convex if

$$
i<\frac{4 p(b+c)^{2}}{(b+4 c)^{2}}+\frac{(1-p)(b+c)}{4 b c}
$$

Now,

$$
\left.\frac{d E[\Pi(g)]}{d g}\right|_{P_{d}^{*}(0)}=-\frac{8 p(b+c)}{b(b+4 c)^{2}} b \delta+2 i\left(\bar{g}-\frac{a c}{b+c}\right)
$$

Thus the curve is upward-sloping in the left neighborhood of $P_{d}^{*}(0)$ if

$$
i<\frac{4 p \delta(b+c)^{2}}{(b+4 c)^{2}[(b+c) \bar{g}-a c]}
$$

Thus whenever the curve is concave, it is upward sloping at $P_{d}^{*}(0)$. Then the optimum in this range is $P_{d}^{*}(0)$. When the curve is convex, the optimum for this range is one of the two corner points: 0 and $P_{d}^{*}(0)$. Thus we now have three candidates for global optimum: 0 , $P_{d}^{*}(0)$ and $\bar{g}$.

Claim $1 P_{d}^{*}(t=0)$ cannot be the optimum for any $i>0$ and $p \in[0,1]$

Proof: Let $G_{u}^{*}$ and $G_{v}^{*}$ be the values of $i$ below which $g=0$ gives lower net profits than that obtained with $g=P_{d}^{*}(t=0)$ and $g=\bar{g}$ respectively. Note that both $G_{u}^{*}$ and $G_{v}^{*}$ are linear functions of $p$. Thus $\triangle_{u}(p)=G_{v}^{*}-G_{u}^{*}$ is linear in $p$. 
Let $p=1$. Whenever $E\left[\Pi\left(P_{d}^{*}\right)\right]=e[\Pi(0)]$, the net profit curve is convex in range $\left[0, P_{d}^{*}(t=\delta)\right]$ and hence $e \Pi\left(P_{d}^{*}\right)=e \Pi(0)<0$. Hence $G_{v}^{*}$ is to the left of $G_{u}^{*}$.

Let $p=0$. Thus $E\left[\Pi\left(P_{d}^{*}\right]<0\right.$. Thus at $i=G_{u}^{*}, E[\Pi(0)]<0$. Thus $G_{v}^{*}$ will be to the left of $G_{u}^{*}$.

Thus $\triangle_{u}(0)<0$ and $\triangle_{u}(1)<0$. Linearity of $\triangle_{u}(p)$ in $p$ ensures that $\triangle_{u}(p)<0 \forall p \in[0,1]$.

Hence, the firm chooses 0 when $E[\Pi(0)]>E[\Pi(\bar{g})]$ and $\bar{g}$ otherwise. Thus the optimal choice of marginal cost is:

$$
g^{Q_{u}}(i)= \begin{cases}0, & \text { if } \quad i<\frac{1}{\bar{g}^{2}}\left[\frac{4 p(a c+b \delta)^{2}}{b(b+4 c)^{2}}+\frac{(1-p) a^{2} c^{2}}{4 b c(b+c)}\right] \\ \bar{g}, & \text { otherwise }\end{cases}
$$

